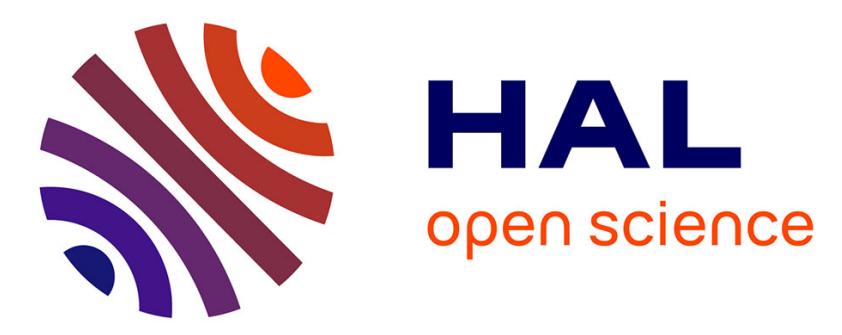

\title{
Streptogramins for the treatment of infections caused by Gram-positive pathogens.
}

Sophie Reissier, Vincent Cattoir

\section{To cite this version:}

Sophie Reissier, Vincent Cattoir. Streptogramins for the treatment of infections caused by Gram-positive pathogens.. Expert Review of Anti-infective Therapy, 2021, pp.1-13. 10.1080/14787210.2021.1834851 . hal-03000655

\section{HAL Id: hal-03000655 \\ https://hal.science/hal-03000655}

Submitted on 5 Feb 2021

HAL is a multi-disciplinary open access archive for the deposit and dissemination of scientific research documents, whether they are published or not. The documents may come from teaching and research institutions in France or abroad, or from public or private research centers.
L'archive ouverte pluridisciplinaire HAL, est destinée au dépôt et à la diffusion de documents scientifiques de niveau recherche, publiés ou non, émanant des établissements d'enseignement et de recherche français ou étrangers, des laboratoires publics ou privés. 


\section{Streptogramins for the treatment of infections caused by Gram-positive pathogens}

Sophie Reissier ${ }^{1}$, Vincent Cattoir 1123

1 Université De Rennes 1, Unité Inserm U1230, Rennes, France.

2 Service De Bactériologie-Hygiène Hospitalière, CHU De Rennes, Rennes, France.

3 Centre National De Référence De La Résistance Aux Antibiotiques (Laboratoire Associé 'Entérocoques'), CHU De Rennes, Rennes, France. 
1 Abstract

2 Introduction: Streptogramins (pristinamycin and quinupristin-dalfopristin) can be interesting

3 options for the treatment of infections due to Gram-positive cocci, especially multidrug4 resistant isolates.

5 Areas covered: This review provides an updated overview on structural and activity 6 characteristics, mechanisms of action and resistance, pharmacokinetic/pharmacodynamic and 7 clinical use of streptogramins.

8 Expert opinion: The streptogramin antibiotics act by inhibition of the bacterial protein 9 synthesis. They are composed of two chemically distinct compounds, namely type A and type 10 B streptogramins, which exert a rapid bactericidal activity against a wide range of Gram11 positive bacteria (including methicillin-resistant staphylococci and vancomycin-resistant 12 enterococci). Several mechanisms of resistance have been identified in staphylococci and 13 enterococci but the prevalence of streptogramin resistance among clinical isolates remains 14 very low. Even if only a few randomized clinical trials have been conducted, the efficacy of 15 pristinamycin has been largely demonstrated with an extensive use for 50 years in France and 16 some African countries. Despite its effectiveness in the treatment of severe Gram-positive 17 bacterial infections demonstrated in several studies and the low rate of reported resistance, the 18 clinical use quinupristin-dalfopristin has remained limited, mainly due to its its poor 19 tolerance. Altogether, streptogramins (especially pristinamycin) can be considered as 20 potential alternatives for the treatment of Gram-positive infections. 


\section{Introduction}

Staphylococci, streptococci and enterococci are major Gram-positive bacterial pathogens causing infections both in the community and in hospitals [1]. Methicillin-resistant Staphylococcus aureus (MRSA) is still a major cause of nosocomial infections, while the emergence of infections caused by community-acquired MRSA (CA-MRSA) has been reported worldwide, especially in the US [2]. Glycopeptides are the first line antibiotics used to treat MRSA infections, but since 1997, S. aureus strains with reduced susceptibility or resistance to glycopeptides have been described and still remain a global concern [3]. Coagulase-negative staphylococci (CoNS) emerged as a major cause of hospital-acquired infections (e.g. catheter-related bacteremia, endocarditis, osteoarticular and neonatal infections) and are often resistant to multiple antibiotics [4-6]. Due to their capacity to acquire and accumulate numerous antibiotic resistance determinants, enterococci, especially vancomycin-resistant Enterococcus faecium (VREF), have become major opportunistic pathogens in hospitals, strongly limiting the range of therapeutic options [7]. Even if widespread use of the pediatric pneumococcal conjugate vaccine has significantly decreased morbidity and mortality of infections due to Streptococcus pneumoniae in all age groups, there has been an unexpected increase of serotypes uncovered by the vaccine (e.g. 35B) as well as antibiotic-resistant serotypes (e.g. 19A) in some regions [8,9].

Besides the emergence of infections caused by multidrug-resistant (MDR) Gram-positive bacteria, which results in a significant increase of morbidity, mortality, and health cost, there is also a paucity of new antibacterial drugs developed by pharmaceutical companies $[10,11]$.

2 Therefore, current antimicrobial alternatives for the treatment of severe infections are scarce, taking account into the risk of the emergence of bacterial resistance, the need of intravenous access, side effects and contraindications[12]. Many complex infections due to these MDR microorganisms (such as prosthetic joint infections) also require prolonged antibiotic therapy, 
46 with an intravenous-to-oral switch therapy. Oral therapeutic options would be also beneficial, 47 for the ambulatory treatment of community-acquired infections.

48 Streptogramins have been considered as potential alternatives for the treatment of Gram49 positive infections, because of their rapid bactericidal activity against a wide range of Gram50 positive bacteria (including MDR strains), their low prevalence of resistance among clinical 51 isolates, and their good pharmacokinetic properties [13,14]. Streptogramins are also effective 52 against Gram-negative cocci such as Neisseria spp or Moraxella catarrhalis. To date, two 53 streptogramins are prescribed in human medicine. Oral pristinamycin (formerly RP 7293), 54 commercialized under the name Pyostacine ${ }^{\circledR}$ (Sanofi-Aventis, Gentilly, France), is extensively used for 50 years in France, and is currently used in France, Tunisia and 56 Lithuania. Quinupristin-dalfopristin (formerly RP 59500), marketed under the name 57 Synercid® (Pzifer, New York), is an injectable formulation approved since 1999 and 2000 in 58 the US and Europe, respectively. Quinupristine-dalfopristine is now only used in the US. 59 Another oral streptogramin, NXL 103 (formerly XRP 2868), underwent phase II clinical trial 60 in 2011 but has not been distributed [15]. Of note, virginiamycin, an oral streptogramin, was 61 therapeutically used in France until late 1990s and as a growth promoter for animals in many 62 European countries until early 2000s and currently in the US, China, Japan and Canada [16]. 63 Virginiamycin is also used to prevent bacterial contamination in ethanol fuel industry [17].

64 Several reviews have already been published about streptogramins but they mainly dealt 65 with structure, mode of action or biosynthesis and its regulation $[16,18]$. Here we have 66 chosen to focus on clinical uses, to synthesize clinical studies on each molecule, current 67 recommendations for use as well as trials about new molecules.

\section{2. Structure}

69 The streptogramin antibiotics are composed of two chemically distinct compounds, namely 70 type A and type B streptogramins [18]. The type A streptogramins are polyunsaturated cyclic 
71 macrolactones (ca. $500 \mathrm{Da}$ ) containing an unusual oxazole ring and a dienyl amide fragment, whereas type B streptogramins are cyclic hepta- or hexadepsipeptides (ca. $800 \mathrm{Da}$ ) with a skeleton of amino acids with variations depending on the compound (Figure 1) [18-20]. Originally, streptogramins are natural mixtures produced by different members of Streptomyces or related genera (Table 1) [19,21]. Every antibiotic producer synthesizes a mixture of various A and B components in different proportions. For instance, Streptomyces pristinaespiralis produces a mixture of group B compounds called pristinamycins I (pristinamycin $\mathrm{I}_{\mathrm{A}}$, pristinamycin $\mathrm{I}_{\mathrm{B}}$, and pristinamycin $\mathrm{I}_{\mathrm{C}}$ with a ratio of $80-90 \%, 3-5 \%$, and 2$5 \%$, respectively) and a mixture of group A compounds called pristinamycins II (pristinamycin $\mathrm{II}_{\mathrm{A}}$ and pristinamycin $\mathrm{II}_{\mathrm{B}}$ ) [19]. Note that pristinamycin $\mathrm{II}_{\mathrm{A}}$ is predominant in the pristinamycin II mixture. The relative proportion of the different pristinamycin II fermentation products also depends on culture conditions [20]. Finally, the pristinamycin produced by $S$. pristinaespiralis is a mixture of pristinamycin $\mathrm{I}_{\mathrm{A}}$ and pristinamycin $\mathrm{II}_{\mathrm{A}}$ in a 30:70 ratio by weight (Table $1 \&$ Figure 1) $[19,20]$.

Since a limitation in the clinical use of streptogramins was the poor water solubility, which prevented the availability of an injectable form for the treatment of severe infections, semisynthetic derivatives were developed in the 1990s from natural pristinamycins (Table 1) [19]. Quinupristin (RP 57669) and dalfopristin (RP 54476) were obtained after several steps of chemical modifications from pristinamycin $\mathrm{II}_{\mathrm{A}}$ and pristinamycin $\mathrm{I}_{\mathrm{A}}$, respectively [19]. The streptogramin association selected, comprised quinupristin and dalfopristin combined in a 30:70 ratio (w/w) of methane sulfonate salts as RP 59500 (Figure 1) [19,20].

\section{Mechanism of action}

Streptogramins A and B act by interfering with bacterial protein synthesis $[22,23]$. Their bindings to adjacent but distinct regions within the P site of 23S rRNA of the 50S ribosomal subunit result in synergic inhibiting activity [24]. Due to cooperative binding, streptogramin 
96 compounds, which are separately bacteriostatic against most Gram-positive bacteria, act 97 synergistically in vitro and in vivo and usually become bactericidal when combined [22].

98 Type A streptogramins block tRNAs attachment to both A and P sites of the peptidyl99 transferase center (PTC), and thus preventing the two early steps of elongation (i.e. 100 aminoacyl-tRNA binding to the A site and peptide bond formation with peptidyl-tRNA at the 101 P site) (Figure 2) [21,22]. Initially, it was thought that streptogramins A were only able to 102 bind to 50S subunits and free $70 \mathrm{~S}$ ribosomes and not to ribosomes involved into protein 103 synthesis and polysomes [22]. However, it has been demonstrated that streptogramins A also 104 interact with the entrance of the peptide exit tunnel, and likely bind to translating ribosomes 105 [25]. Type B streptogramins share overlapping binding sites with macrolides and 106 lincosamides (domains II and $\mathrm{V}$ of the $23 \mathrm{~S}$ rRNA), and act similarly by inhibiting 107 translocation, preventing polypeptide extension, and triggering the premature release of 108 incomplete protein chains $[21,22]$. Streptogramins B binding site is located at the entrance to 109 the ribosome tunnel, and does not contact the PTC (Figure 2) [26]. They can interact with 110 ribosomes at any step of protein synthesis, including translating ribosomes and polysomes, 111 inhibiting elongation after a few cycles [22].

112 In addition, binding of type A streptogramins induces a conformational change in the 113 ribosome near the PTC that subsequently unmasks a high-affinity binding site for 114 streptogramins B leading to an increase of their activity by ca. 100-fold [18,21,22]. This 115 synergy in the binding of streptogramins A and B seems to result from a repositioning of a 116 single nucleotide, A2062 (Escherichia coli numbering), permitting direct interactions between 117 both compounds [26,27]. Finally, the bactericidal activity of streptogramins may be partially 118 due to the induction of a conformational alteration of U2585, leading to a hydrogen-bond119 stabilized distortion of the PTC [26].

\section{4. Antibacterial activity}


121 The spectrum of activity of streptogramins includes a broad range of aerobic and anaerobic 122 Gram-positive bacteria, with a $\mathrm{MIC}_{90}$ generally $\leq 1 \mathrm{mg} / \mathrm{l}$ (Table 2) [28-33]. They are active 123 against methicillin-susceptible, MRSA and most of E. faecium isolates (including VREF) 124 (Table 2) [30,34]. Noteworthy, Enterococcus faecalis is a gap in the antimicrobial spectrum 125 since this Gram-positive species is intrinsically resistant to type A streptogramins (phenotype $126 \mathrm{LS}_{\mathrm{A}}$, which results in lincosamide and streptogramins $\mathrm{A}$ resistance) and to the A plus $\mathrm{B}$ 127 streptogramin combinations, due to the presence of the $l s a(\mathrm{~A})$ gene [35-37]. Streptogramins 128 are also active against S. pneumoniae (regardless of resistance to $\beta$-lactams and macrolides), $129 \beta$-hemolytic streptococci, viridans streptococci, Corynebacterium spp., and Listeria 130 monocytogenes (Table 2) [28,38,39]. In addition, streptogramins exhibit activity against most 131 of Gram-positive anaerobes, such as Actinomyces spp., Clostridium spp., Lactobacillus spp., 132 Peptostreptococcus spp., and Cutibacterium acnes (Table 2) [33,39]. They are also active 133 against Mycoplasma spp., Ureaplasma urealyticum, and Chlamydia spp. Indeed, European 134 guidelines about $M$. genitalium infections recommend pristinamycin as third-line therapy in 135 patients failing both azithromycin and moxifloxacin therapy [40,41]. Interestingly, they also 136 have a good activity against fastidious Gram-negative bacteria including Moraxella 137 catarrhalis, Neisseria spp., and Legionella pneumophila (Table 2) [28,38,39]. Streptogramins 138 have a variable activity against Bacteroides fragilis group and other Gram-negative 139 anaerobes. Several strains are resistant and some, like Fusobacterium spp. are very 140 susceptible (Table 2) [28,39,40]. Finally, Enterobacterales, Pseudomonas aeruginosa, and 141 Acinetobacter spp. are intrinsically resistant to high levels of streptogramins [28].

142 Clinical Laboratory Standards Institute breakpoints for quinupristin-dalfopristin against 143 staphylococci, enterococci, and streptococci are as follows: $\leq 1 \mathrm{mg} / \mathrm{l}$, susceptible; $2 \mathrm{mg} / \mathrm{l}$, 144 intermediate; and $\geq 4 \mathrm{mg} / \mathrm{l}$, resistant [42]. European Committee of Antimicrobial 145 Susceptibility Testing breakpoints for quinupristin-dalfopristin are available only for 
146 staphylococci $(\leq 1 \mathrm{mg} / 1$, susceptible; $>2 \mathrm{mg} / \mathrm{l}$, resistant $)$ and enterococci $(\leq 1 \mathrm{mg} / 1$, susceptible; $147>4 \mathrm{mg} / \mathrm{l}$, resistant) (www.eucast.org/). The Antibiogram Committee of the French Society 148 only recommends breakpoints for pristinamycin for Microbiology (www.sfm149 microbiologie.org) as follows: $\leq 1 \mathrm{mg} / \mathrm{l}$, susceptible and $>2 \mathrm{mg} / \mathrm{l}$, resistant, for staphylococci, 150 enterococci, streptococci (except $S$. pneumoniae), and anaerobes; $\leq 1 \mathrm{mg} / 1$, susceptible and $>1$ $151 \mathrm{mg} / \mathrm{l}$, resistant, for S. pneumoniae.

152 Streptogramins are usually rapidly bactericidal against methicillin-susceptible 153 staphylococci, streptococci, and pneumococci regardless of erythromycin resistance, with 154 minimum bactericidal concentration (MBC) values usually $\leq 4$-fold higher than those of MICs 155 [29]. However, the bactericidal activity against staphylococci expressing a constitutive cross156 resistance to macrolides, lincosamides, and streptogramins B (like numerous MRSA isolates, 157 see below) is generally altered [43]. For this reason, clindamycin susceptibility has been 158 suggested as a surrogate marker for bactericidal activity of quinupristin-dalfopristin against 159 staphylococci $[44,45]$. Streptogramins have a bacteriostatic activity against the majority of $E$. 160 faecium isolates [39]. Against MRSA, rifampin has been demonstrated to be synergistic with 161 quinupristin-dalfopristin while it has been shown a synergism with doxycycline against VREF $162[29,46]$. Furthermore, the association with doxycycline may prevent or delay the emergence 163 of resistance in vitro and in vivo among VREF isolates [29,46,47].

\section{5. Mechanisms of resistance to streptogramins A and B}

165 Most Gram-negative bacteria are intrinsically resistant to streptogramins, owing to the low 166 permeability of the outer membrane and active efflux mechanisms. As already mentioned, 167 type A and B streptogramins are chemically unrelated and have different binding sites on the 168 ribosome. Therefore, different mechanisms will confer resistance to each type of 169 streptogramins. In Gram-positive organisms, a variety of mechanisms confer resistance to 170 either the $\mathrm{A}$ or the $\mathrm{B}$ component, including modifying enzymes, and modification or 
171 protection of the ribosomal target (Table 3 , Figure 3 )

172 (http://faculty.washington.edu/marilynr/) [20,21,48-51].

173 The alteration of the ribosomal target is the most common resistance mechanism to type B 174 streptogramins [20,21,49-51]. It is mainly due to the post-transcriptional modification of the 175 23S rRNA (domain V) by an rRNA methylase encoded by erm genes (Table 3) [20,21,24,49176 51]. Plasmid-borne or transposable erm genes encode a ribosomal methylase that mono- or 177 dimethylates the $\mathrm{N}^{6}$ of A2058 (E. coli numbering) of the 23S rRNA. This methylation leads to 178 an alteration of binding of streptogramins B to their target, knowing that the A2058 is the 179 binding site not only for streptogramins B but also for macrolides and lincosamides, which 180 have partially overlapping binding sites. This is the reason why this modification confers 181 cross-resistance to macrolides, lincosamides, and streptogramins B (the so-called MLS $_{B}$ 182 phenotype) [20]. To date, more than 40 different erm genes have been described 183 (http://faculty.washington.edu/marilynr/) [48,50-55]. Expression of $\mathrm{MLS}_{\mathrm{B}}$ resistance can be 184 constitutive or inducible [20]. In inducible resistance, only the use of erythromycin (and other 185 14- and 15-membered macrolides) is prohibited, clindamycin and streptogramins B are 186 remain active. When erm genes are expressed constitutively, they confer cross-resistance both 187 to macrolides, clindamycin, and streptogramins B. Mutations of 23S rRNA and L22 188 ribosomal proteins, which lead to resistance to streptogramins B, have also been reported, 189 particularly in S. pneumoniae (Table 3) [20,48,56].

190 Other mechanisms affecting the activity of type B streptogramins are enzymatic 191 modification (hydrolysis) and ribosome protection. Lyases and lactonases, enzymes encoded 192 by $v g b$ genes, could inactivate streptogramins B (Table 3) [20,21,48,50,51]. They cause a 193 cleavage of the ester linkage leading to a linearization of the molecule. A Low-level of 194 resistance to streptogramins B, mediated by ribosomal protection through acquisition of $m s r$ 195 like genes, is described in staphylococci, streptococci, or enterococci [57]. 
196 Drug modification and target modification or protection account for resistance to 197 streptogramins A [20,21,48-51]. Ribosomal methylation, occurring at a different site than the 198 A2058 previously mentioned, may confer resistance to type-A streptogramins. Initially 199 identified in staphylococcal isolates from animal sources, the ribosomal methylation 200 mechanism has been also detected in human S. aureus clinical isolates [58-63]. The 201 resistance is due to the production of the Cfr protein that methylates the 23S rRNA at the 202 A2503 residue (E. coli numbering) (Table 3) [64]. Interestingly, Cfr is responsible for a 203 cross-resistance to five different antibiotic families: phenicols, lincosamides, oxazolidinones, 204 pleuromutilins, and streptogramins A (the so-called $\mathrm{PhLOPS}_{\mathrm{A}}$ phenotype) [65]. Usually found 205 on plasmids, the $c f r$ gene has also been reported to be encoded on chromosomes $[61,66]$. Type 206 A streptogramins can be inactivated through the O-acetylation by acetyltransferases encoded 207 by vat genes (Table 3) [20,21,49-51]. Vat enzymes add an acetyl group from acetyl-CoA to 208 the second hydroxyl of type A streptogramins. Several proteins belonging to the ABC 209 proteins family including Lsa and Vga proteins are responsible for streptogramin A resistance 210 in E. faecalis and staphylococci through ribosomal protection $[48,57,67]$. Mutations in eat(A), 211 which is coding for a $\mathrm{ABC}$ protein and conferred acquired $\mathrm{LS}_{\mathrm{A}}$ resistance, has also described 212 in E. faecium [68].

6. Consequences of resistance mechanisms on synergism between streptogramins $A$ and 214 B

215 In staphylococci, it is possible to select in vitro some mutants resistant to quinupristin216 dalfopristin, but the frequency remains low $\left(10^{-8}\right.$ to $\left.10^{-9}\right)$ [29]. However, a higher rate of 217 selection has been demonstrated in E. faecium [29]. Because of the synergism, acquisition of 218 resistance to each streptogramin type might have no or only partial negative impact on the 219 antimicrobial activity of the combination [20]. Actually, most staphylococcal clinical isolates 220 that express complete resistance to the combination harbour several streptogramin resistance 
genes such as $\operatorname{vat}(\mathrm{A}), \operatorname{vg} b(\mathrm{~A}), \operatorname{vga}(\mathrm{A}), \operatorname{vga}(\mathrm{B})$ or $\operatorname{vat}(\mathrm{B}[16,48]$. In these isolates, vat(A), $v g b(\mathrm{~A})$, and $v g a(\mathrm{~A})$ or $v g a(\mathrm{~B})$ and $v a t(\mathrm{~B})$ genes are often associated on plasmids of $26-40 \mathrm{~kb}$ and 50-90 kb, respectively [69]. Although streptogramin-resistant clinical isolates of $S$. aureus and E. faecium containing such plasmids have already spread, their prevalence remains low [69]. Resistance to the $\mathrm{B}$ component of streptogramins due to the constitutive MLS $_{\mathrm{B}}$ phenotype is widespread in staphylococci and streptococci $[20,48]$. It has been early shown 227 that the synergism between type A and B components is maintained against clinical isolates of staphylococci and streptococci constitutively resistant to macrolides. The original observation of synergy preservation was done with pristinamycin, and was confirmed for quinupristin230 dalfopristin [70,71]. Conservation of synergism is likely due to the unique and synergic mode 231 of action of streptogramins (see above). However, as previously mentioned, the in vitro 232 bactericidal activity of the combination is altered in staphylococci expressing the $\operatorname{MLS}_{\mathrm{B}}$ 233 constitutive phenotype. Three studies using an experimental model of aortic endocarditis in 234 rabbit or in rat indicated decreased in vivo efficacy of quinupristin-dalfopristin against MLS $_{\mathrm{B}^{-}}$ 235 resistant strains of $S$. aureus and E. faecium [72-74]. In one study, failure was imputed to the 236 short plasmatic half-life of dalfopristin, highlighting the importance of the individual kinetics 237 of each component of the combination [74]. Another study showed a maintained in vivo 238 efficacy of quinupristin-dalfopristin against a $S$. aureus strain constitutively expressing an $239 \operatorname{erm}(\mathrm{A})$ gene [75]. Unfortunately, no large clinical studies are available to provide a definitive 240 answer.

241 When strains express the inducible $\mathrm{MLS}_{\mathrm{B}}$ phenotype, they remain susceptible to 242 clindamycin and type B streptogramins. However, concern over the possibility of selection of 243 constitutive mutants resistant to clindamycin during therapy has led to discourage clinicians 244 from prescribing streptogramin antibiotics. Similarly, the capacity of type B streptogramins to 245 select constitutively resistant mutants was described [70]. However, the emergence of mutants 
246 was prevented in vitro if the cultures were exposed to type A streptogramins, suggesting that 247 such mutants were unlikely to be selected in vivo when applying the streptogramin 248 combination [70].

\section{7. Epidemiology of resistance}

250 Although rare, resistance to streptogramins has been reported in E. faecium isolates 251 recovered from patients treated with quinupristin-dalfopristin $[49,76]$. This resistance was 252 associated with clinical failure and persistent VREF infections in almost all cases [49]. Other 253 streptogramin-resistant E. faecium isolates have also been recovered from humans in Europe 254 and in the US [77]. The rate of resistance to quinupristin-dalfopristin is usually $\leq 10 \%$ but 255 higher rates have been reported in Europe (up to 30\%) [78-80]. A major concern is the 256 resistance among E. faecium isolates from animal sources that appears to be more common 257 (up to $100 \%$ ) [49]. This is likely related to the extensive use of streptogramins in animal 258 husbandry (as growth factors) and veterinary medicine [16]. Whereas virginiamycin is still 259 approved by the US FDA to promote growth and prevent or control disease in chickens, 260 turkeys, swine, and cattle, it has been banned since 1999 in Europe [16]. The emergence of 261 streptogramin-resistant E. faecium isolates seems to be substantially the result of 262 virginiamycin use in animals and the transfer of streptogramin resistance via food to humans 263 [49,81]. In staphylococci (MRSA and CoNS), prevalence of resistance to quinupristin264 dalfopristin remains very low $(<1 \%)$ [82].

265 Despite the longstanding oral use of streptogramins in France, the frequency of resistance 266 to pristinamycin remains low in $S$. aureus and CoNS (usually <5-10\%) [83]. In North 267 America, resistance to quinupristin-dalfopristin has been infrequently observed, where more 268 than $98 \%$ of $S$. aureus (including CA-MRSA) and CoNS isolates are entirely susceptible $269[44,78,79,84-86]$. Although macrolide resistance in $\beta$-hemolytic streptococci is common, 270 high-level streptogramin resistance has not been reported yet. However, several S. agalactiae 
271 isolates from New Zealand and USA expressed $l s a(\mathrm{C})$ or $l s a(\mathrm{E})$ genes and expressed $\mathrm{LS}_{\mathrm{A}}$ 272 phenotype [87,88]. Among pneumococci and viridans streptococci, resistance to quinupristin273 dalfopristin is very uncommon, with more than $99 \%$ and $97 \%$ of susceptible strains, 274 respectively $[84,86]$. In France, all strains of $S$. pneumoniae isolated in adults and children 275 were susceptible to pristinamycin in 2016 [89].

\section{8. Pharmacokinetics and Pharmacodynamics}

277 The two main components of pristinamycin (i.e. $\mathrm{PI}_{\mathrm{A}}$ and $\mathrm{PII}_{\mathrm{A}}$ ) exhibit nearly parallel 278 plasma kinetics (Table 4) [90]. They are both quite rapidly absorbed, especially with 279 concomitant food intake ( $\mathrm{t}_{\max }, 1 \mathrm{~h}$ vs. $\left.3 \mathrm{~h}\right)$ [90]. Although few data on its metabolism are 280 available, pristinamycin is mainly eliminated in the bile and poorly penetrates into cerebral 281 spinal fluid. Only scarce data are available on the diffusion in other biological fluids and into 282 tissues, in particular bone.

283 Due to its minimal oral absorption, quinupristin-dalfopristin is only administered 284 intravenously, at a fixed 30:70 ratio. A linear relationship between dose and maximum plasma 285 concentration $\left(\mathrm{C}_{\max }\right)$ has been observed $[29,91]$. The main pharmacokinetic parameters after a 286 single $7.5 \mathrm{mg} / \mathrm{kg}$ infusion over $1 \mathrm{~h}$ are shown in Table 4 [29,91]. After multiple doses (7.5 $287 \mathrm{mg} / \mathrm{kg} \mathrm{q} 8 \mathrm{~h}$ or q12h), steady state is achieved by day 2 and there is an increase of ca. $20 \%$ in $288 \mathrm{C}_{\max }$ and AUC for both components [29,91]. Quinupristin exhibits higher, although moderate, 289 protein binding than dalfopristin (Table 4) [29,91]. Both quinupristin and dalfopristin 290 distribute well into tissues, such as kidneys, liver, spleen, salivary glands, and into white 291 blood cells, but the penetration into the CSF is poor [29,91]. Extravascular penetration into 292 blister fluid is approximately $40 \%$ of that of the plasma $[29,91]$. The diffusion of radiolabeled 293 quinupristin and dalfopristin, alone or in combination, in aortic vegetations from experimental 294 endocarditis in rabbits was also evaluated [92]. Quinupristin was homogeneously distributed 295 throughout the vegetations whereas dalfopristin showed a decreasing gradient of 
296 concentration between the periphery and the core of the vegetation. Both compounds are 297 rapidly metabolized via non-enzymatic reactions [29,91]. Quinupristin is converted in two 298 active metabolites; a glutathione-conjugated compound (RP 69012) and a cysteine-conjugated 299 compound (RPR 100391) whereas dalfopristin is hydrolyzed to the natural pristinamycin $\mathrm{II}_{\mathrm{A}}$ 300 (RP 12536). Importantly, these metabolites exhibit antibacterial activity similar to that of the 301 parental compounds. Quinupristin-dalfopristin is hepatically cleared and excreted through the 302 biliary tract (Table 4) [29,91]. Quinupristin and dalfopristin exhibit a biphasic elimination, 303 and distribution half-life $\left(\mathrm{t}_{1 / 2}\right)$ values of their metabolites are slightly longer $(\times 1.1-1.5)$ 304 [29,91]. After administration of multiples doses, clearance of quinupristin-dalfopristin is 305 decreased by ca. $20 \%$. Age, gender, and obesity appear to have no clinically significant 306 impact [29,91]. Finally, no dosage adjustments are necessary in patients with renal 307 impairment (including those under hemodialysis) and mild-to-moderate hepatic disease $308[29,91]$. The ratio AUC to MIC (AUC/MIC) seems to be the most predictive PK/PD 309 parameter of quinupristin-dalfopristin for antibacterial activity against $S$. aureus and $S$. 310 pneumoniae [91]. In addition, this association possesses an extended post-antibiotic effect 311 (PAE) against most of Gram-positive pathogens, which varies from approximately 4 to $5 \mathrm{~h}$ (at 312 4-fold MIC) in S. aureus and S. epidermidis [29]. At 4-fold MIC, a prolonged PAE is also 313 observed for S. pneumoniae (ca. 8 h), S. pyogenes (ca. 9-10 h), and S. agalactiae (ca. 7 h) 314 [29]. Finally, it has a PAE around 4-5 h (at 4-fold MIC) against E. faecium, even if it may be 315 as short as $0.2-1 \mathrm{~h}$ for some VREF strains [29,91].

\section{9. Clinical use}

317 Even if there are only a few randomized clinical trials to support the use of pristinamycin, 318 oral and topical preparations have been used in some European countries (particularly in 319 France) for more than 50 years, its efficacy has been largely demonstrated in humans 320 throughout this long period of time. In France, pristinamycin is primarily indicated for the 
321 management of staphylococcal and streptococcal infections in adults (2-3 g/day) and children 322 (50 mg/kg/day): sinusitis, bronchopulmonary and skin infections. Two double-blind 323 randomized multicenter studies have demonstrated the non-inferiority of pristinamycin versus 324 cefuroxime axetil in the treatment of acute sinusitis in adults (Table 5) [93,94]. Two large 325 multicenter studies have also validated the use of pristinamycin in the treatment of 326 community-acquired pneumonia and another in chronic obstructive pulmonary disease acute 327 exacerbations (Table 5) [95-97]. A multicenter phase IV french study comparing the efficacy 328 of pristinamycin ( $2 \mathrm{~g}$ x 2 per day for 2 days then $1 \mathrm{~g}$ × 3 per day for 5 to 7 days) versus 329 amoxicillin ( $1 \mathrm{~g} \times 3$ per day for 7 to 9 days) in adults with acute community acquired 330 pneumonia is currently undergoing (www.clinicaltrials.gov; NCT02332577). Several 331 prospective studies have also demonstrated that pristinamycin was a good alternative to treat 332 skins infections, such as erysipelas and superficial pyodermas (Table 5)[98-101]. 333 Pristinamycin is not recommended as a first-line treatment for osteo-articular and bone joint 334 infections but several retrospective studies have described its clinical utility for (success rate 335 ca. 70\%) [13,102,103]. Pristinamycin was also effective for MDR Gram-positive infections 336 treatment, especially MRSA (success rates ca. 80\%) [102,104-106]. Several studies showed 337 that pristinamycin might be useful in management of Mycoplasma genitalium infections 338 [107,108]. Since 2016, European guidelines recommended to use pristinamycin as a third-line 339 treatment after azithromycin and moxifloxacin treatment failure for M. genitalium infections, 340 an important sexually transmitted pathogen responsible for both male and female genital tract 341 disease [40]. Finally, In 2016, Teng et al. demonstrated that pristinamycin was a good 342 alternative to treat infections due to resistant Gram-positive bacteria in patients with cancer $343[14]$.

344 Quinupristin-dalfopristin was firstly investigated on an emergency-use basis in the 345 treatment of infections attributable to MDR Gram-positive bacteria, such as MRSA and 
346 VREF [29]. Its efficacy in the treatment of MRSA infections was documented in case reports, 347 a comparative pilot study and two phase III studies, with clinical success rates consistently 348 higher than 60\% (Table 5) [29,109]. In a small single-blind randomized study, quinupristin349 dalfopristin has been also found to achieve similar response rates to vancomycin for the 350 treatment of catheter-related bloodstream infections (Table 5) [110]. The efficacy of 351 quinupristin-dalfopristin in the treatment of VREF infections was determined in three large 352 prospective phase III studies, with clinical and bacteriological success rates between 50 and $35370 \%$ (Table 5) [111-113]. The overall response rates varied according to the site of infection $354(<45 \%$ for endocarditis, intra-abdominal and intravascular infections) [111]. It is important to 355 note that the treatment with quinupristin-dalfopristin may also favor an E. faecalis 356 superinfection, because of the antimicrobial spectrum of quinupristin-dalfopristin excluded $E$. 357 faecalis [111]. Two large randomized open multicenter trials have compared quinupristin358 dalfopristin with standard therapy in patients suffering from presumed Gram-positive 359 complicated skin and soft-tissue infections (SSSIs) with similar clinical and bacteriological 360 success rates in the two groups (Table 5) [29,114]. For the treatment of nosocomial 361 pneumonia, the efficacy of quinupristin-dalfopristin plus aztreonam versus vancomycin plus 362 aztreonam was tested in a randomized, non-blind, multicenter study, and the equivalence of 363 the two antimicrobial regimens was demonstrated (Table 5) [115]. Quinupristin-dalfopristin 364 was also used successfully to treat a variety of infections, such as cellulitis, catheter-related 365 bacteremia, osteomyelitis, peritonitis, septic arthritis/bursitis, and wound infections [29]. 366 Finally, a single study has reported a clinical benefit (favorable clinical and microbiological 367 response rates at $69 \%$ and $78 \%$, respectively) in pediatric patients with severe Gram-positive 368 infections [116]. Since 1999, the association quinupristin-dalfopristin is approved by the USA 369 FDA for complicated SSSIs caused by oxacillin-susceptible S. aureus and S. pyogenes. In 370 1999, quinupristin-dalfopristin was also approved for the treatment of severe infections due to 
371 VREF associated with bacteremia, but approval was removed by USA FDA in 2010. In 2015,

372 European Society of Cardiology recommended to use quinupristin-dalfopristin to treat 373 infective endocarditis due to aminoglycosides, beta-lactams and vancomycin resistant $E$. 374 faecium [117]. The efficacy of the streptogramin combination in infections due to 375 clindamycin-resistant staphylococci (mostly hospital-acquired MRSA) remains controversial. 376 The recommended dosages of quinupristin-dalfopristin are $7.5 \mathrm{mg} / \mathrm{kg}$ every $12 \mathrm{~h}$ for 377 complicated SSTIs and $7.5 \mathrm{mg} / \mathrm{kg}$ every $8 \mathrm{~h}$ for VRE infections (IV infusion over $1 \mathrm{~h}$ ).

378 Another oral streptogramin have been developed, named NXL103. Two multicenter, 379 randomized, phase II clinical trials have been conducted in 2007 and 2009 (Table 5). The first 380 one evaluated NXL103 efficacy, safety and tolerance for the treatment of community381 acquired pneumonia in adults (www.clinicaltrials.gov, NCT00653172). The second one 382 evaluated NXL103 to treat acute bacterial skin infections (www.clinicaltrials.gov, 383 NCT00949130). Those two studies were stopped in 2009 and 2010 respectively. No clinical 384 data has been published since then.

\section{Adverse effects and drug interactions}

387 Pristinamycin is generally well tolerated, with gastrointestinal disturbances (incidence ca. $3887-25 \%$ ) being the most frequent adverse events (nausea, vomiting, diarrhea), while some skin 389 rashs, arthralgia or myalgia have been also reported [13,94,118].

390 The two major adverse effects of quinupristin-dalfopristin are venous intolerance 391 (incidence $>50 \%$ ), and arthralgia or myalgia (incidence, 2-30\%), which can be severe [39]. 392 Administration of quinupristin-dalfopristin requires the presence of a central venous catheter 393 because of venous toxicity, which is an important limitation to its use [39]. Other common 394 adverse events (incidence, 2-4\%) include nausea, vomiting, diarrhea, and rash [39]. 395 Biologically, an elevation of conjugated bilirubin may be observed [39]. Quinupristin and 
396 dalfopristin are inhibitors of CYP3A4 and consequently drug interaction is observed with 397 ciclosporin, midazolam, nifedipine, tamoxifen, and terfenadine [39,91].

398 11. Conclusion

399 Streptogramin antibiotics are a combination of chemically unrelated compounds, namely 400 type A and type B streptogramins, which act synergistically by inhibiting protein synthesis. 401 Although the streptogramin compounds are separately bacteriostatic, the combination usually 402 becomes bactericidal. Their spectrum of activity includes a broad range of aerobic and 403 anaerobic Gram-positive bacteria, but also most of fastidious Gram-negative and atypical 404 bacteria. This synergism also allows overcoming certain mechanisms of resistance to the 405 individual components of the combination and may explain low rates of resistance reported so 406 far. To date, two streptogramins are available in human medicine, oral pristinamycin, and 407 quinupristin-dalfopristin, an injectable formulation approved since 1999 and 2000 in the US 408 and Europe, respectively. In this study we have synthesized all the clinical studies evaluating 409 these antibiotics. Finally, virginiamycin, an oral streptogramin, was therapeutically used in 410 France until late 1990s and as a growth promoter for animals in many European countries 411 until early 2000s and currently in the US. 


\section{Expert opinion}

414 Pristinamycin and quinupristin-dalfopristin are the two streptogramins used in human

415 medicine. They are a combination of two compounds that are bacteriostatic separately but 416 have bactericidal activity when used synergistically. The mechanism of the synergy is unique 417 and based on a stable ribosome conformational change provoked by the binding of 418 streptogramins A that unmasks a high-affinity binding site for streptogramins B. Using 419 combined antimicrobials to achieve synergism and enhance antimicrobial activity is not a new 420 concept. This notion has already proven to be correct for antimicrobial combinations 421 developed as a single drug such as trimethoprim combined with sulfamethoxazole 422 (cotrimoxazole), which sequentially inhibit two different enzymatic steps of the same 423 metabolic pathway (i.e. synthesis of folic acids). In addition, if the synergism is conserved 424 despite resistance to one of the components, this should avoid resistance to the combination. 425 The value of the synergy strategy has been highlighted by the maintained in vitro activity of 426 the streptogramin combination against most strains that are resistant to either type of 427 streptogramins and by the low frequency of resistant isolates in France despite the use of 428 pristinamycin for more than 50 years.

429 Nonetheless, an important issue for clinical use of streptogramins is the specific 430 pharmacokinetics of each component of the combination that needs to reach the bacterial 431 pathogen at the site of infection in a ratio allowing synergism. This is particularly true for 432 strains that are resistant to one of the streptogramin components.

433 Pristinamycin is mainly used in France until now to treat sinusitis, bronchopulmonary and 434 skin infections due to streptococci or staphylococci. This antibiotic is easy to use because of 435 its non-invasive route of administration, oral or topical. In addition, pristinamycin is well 436 tolerated with few side effects; it also has few interactions with other drugs and is 437 inexpensive. Currently, pristinamycin is recommended to treat sinusitis, bronchopulmonary 
438 infections and skin infections due to streptococci or staphylococci. M. genitalium is an 439 important sexually transmitted pathogen responsible for both male and female genital tract 440 disease. Recently, the interest of pristinamycin in the treatment of infections due to this 441 pathogen have been demonstrated and European guidelines recommend to use pristinamycin 442 as a third-line treatment after azithromycin and moxifloxacin treatment failure for $M$. 443 genitalium infections. Moreover, this antibiotic has been described to be a good alternative to 444 treat infections due to resistant Gram-positive bacteria in patients with cancer in an Australian 445 study.

446 Quinupristin-dalfopristin, an injectable streptogramin, was the first to be developed 447 internationally. Despite its effectiveness in the treatment of severe Gram-positive bacterial 448 infections demonstrated in several studies, and the low rate of reported resistance, the 449 penetration of this molecule into the antibiotic market has remained limited. This can be 450 probably explained in part by the mode of administration, which requires a central venous 451 catheter. The low use of this antibiotic can likely also be explained by the high prevalence of 452 side effects, namely venous intolerance and the risk of thrombophlebitis. Studies to decrease 453 the toxicity of this molecule would be interesting, in order to make it more accessible and 454 easy to use. Currently marketed in North America, its high cost also represents a barrier to its 455 use.

\section{Financial \& competing interests disclosure}

458 The authors have no other relevant affiliations or financial involvement with any 459 organization or entity with a financial interest in or financial conflict with the subject matter 460 or materials discussed in the manuscript.

461 No writing assistance was utilized in the production of this manuscript. 
463

Key issues

464 - Streptogramins are a bactericidal combination of two compounds, streptogramins A 465 and B that act synergistically by inhibition of bacterial protein synthesis.

466

- Two streptogramins (pristinamycin and quinupristin-dalfopristin) are currently used in human medicine.

- Streptogramins exhibit a rapid bactericidal activity against a wide range of Grampositive bacteria (including multidrug-resistant isolates)

- Several mechanisms of resistance have been identified in staphylococci and enterococci but their prevalence among clinical isolates remains very low

- The efficacy of pristinamycin has been largely demonstrated due to its extensive use for 50 years in France and some African countries.

- The clinical use quinupristin-dalfopristin has remained limited, mainly due to its poor tolerance

- Streptogramins (especially pristinamycin) can be considered as potential alternatives for the treatment of Gram-positive infections 


\section{References}

480 [1] Woodford N, Livermore DM. Infections caused by Gram-positive bacteria: a 481

[2] David MZ, Daum RS. Community-associated methicillin-resistant Staphylococcus aureus: epidemiology and clinical consequences of an emerging epidemic. Clin Microbiol Rev. 2010;23:616-87.

[3] Zhang S, Sun X, Chang W, Dai Y, Ma X. Systematic Review and meta-analysis of the epidemiology of Vancomycin-Intermediate and Heterogeneous VancomycinIntermediate Staphylococcus aureus Isolates. PloS One. 2015;10:e0136082.

[4] Berlak N, Shany E, Ben-Shimol S, et al. Late onset sepsis: comparison between coagulase-negative staphylococci and other bacteria in the neonatal intensive care unit. Infect Dis. 2018;0:1-7.

[5] Bor DH, Woolhandler S, Nardin R, Brusch J, Himmelstein DU. Infective Endocarditis in the U.S., 1998-2009: A Nationwide Study. PLOS ONE. 2013;8:e60033.

[6] von Eiff C, Peters G, Heilmann C. Pathogenesis of infections due to coagulasenegative staphylococci. Lancet Infect Dis. 2002;2:677-85.

[7] O’Driscoll T, Crank CW. Vancomycin-resistant enterococcal infections: epidemiology, clinical manifestations, and optimal management. Infect Drug Resist. 2015;8:217-30.

[8] Wantuch PL, Avci FY. Current status and future directions of invasive pneumococcal diseases and prophylactic approaches to control them. Hum Vaccines Immunother. 2018;0:1-19.

[9] Chochua S, Metcalf BJ, Li Z, et al. Invasive serotype 35B pneumococci including an expanding serotype switch lineage, United States, 2015-2016. Emerg Infect Dis. 2017;23:922-30.

[10] Devasahayam G, Scheld WM, Hoffman PS. Newer antibacterial drugs for a new century. Expert Opin Investig Drugs. 2010;19:215-34.

[11] Theuretzbacher U. Future antibiotics scenarios: is the tide starting to turn? Int J Antimicrob Agents. 2009;34:15-20.

[12] Abbas M, Paul M, Huttner A. New and improved? A review of novel antibiotics for Gram-positive bacteria. Clin Microbiol Infect. 2017;23:697-703.

[13] Cooper EC, Curtis N, Cranswick N, Gwee A. Pristinamycin: old drug, new tricks? J Antimicrob Chemother. 2014;69:2319-25.

[14] Teng JC, Lingaratnam SM, Trubiano JA, Thursky KA, Slavin MA, Worth LJ. Oral pristinamycin for the treatment of resistant Gram-positive infections in patients 
with cancer: Evaluation of clinical outcomes. Int J Antimicrob Agents.

2016;47:391-6.

517

518

519

520

521

522

523

524

525

526

527

528

529

530

531

532

533

534

535

536

537

538

539

540

541

542

543

544

545

546

547

548

549

550

551

552

[15] Politano AD, Sawyer RG. NXL-103, a combination of flopristin and linopristin, for the potential treatment of bacterial infections including community-acquired pneumonia and MRSA. Curr Opin Investig Drugs Lond Engl 2000. 2010;11:225-36.*

\section{* Study about the NXL103, the last oral streptogramin developed}

\section{[16] Mast Y, Wohlleben W. Streptogramins - Two are better than one! Int J Med Microbiol. 2014;304:44-50. *}

\section{* Most recent complete review on streptogramin biosynthesis and its regulation}

[17] Bischoff KM, Zhang Y, Rich JO. Fate of virginiamycin through the fuel ethanol production process. World J Microbiol Biotechnol. 2016;32:76.

[18] Mukhtar TA, Wright GD. Streptogramins, oxazolidinones, and other inhibitors of bacterial protein synthesis. Chem Rev. 2005;105:529-42.

[19] Barrière JC, Berthaud N, Beyer D, Dutka-Malen S, Paris JM, Desnottes JF. Recent developments in streptogramin research. Curr Pharm Des. 1998;4:155-80.

[20] Canu A, Leclercq R. Overcoming bacterial resistance by dual target inhibition: the case of streptogramins. Curr Drug Targets Infect Disord. 2001;1:215-25.

[21] Johnston NJ, Mukhtar TA, Wright GD. Streptogramin antibiotics: mode of action and resistance. Curr Drug Targets. 2002;3:335-44.

[22] Cocito C, Di Giambattista M, Nyssen E, Vannuffel P. Inhibition of protein synthesis by streptogramins and related antibiotics. J Antimicrob Chemother. 1997;39 Suppl A:7-13.

[23] Vannuffel P, Cocito C. Mechanism of action of streptogramins and macrolides. Drugs. 1996;51 Suppl 1:20-30.

[24] Poehlsgaard J, Douthwaite S. The bacterial ribosome as a target for antibiotics. Nat Rev Microbiol. 2005;3:870-881.

[25] Hansen JL, Moore PB, Steitz TA. Structures of five antibiotics bound at the peptidyl transferase center of the large ribosomal subunit. J Mol Biol. 2003;330:1061-75.

[26] Harms JM, Schlünzen F, Fucini P, Bartels H, Yonath A. Alterations at the peptidyl transferase centre of the ribosome induced by the synergistic action of the streptogramins dalfopristin and quinupristin. BMC Biol. 2004;2:4.

[27] Tu D, Blaha G, Moore PB, Steitz TA. Structures of MLSBK antibiotics bound to mutated large ribosomal subunits provide a structural explanation for resistance. Cell. 2005;121:257-70. 
553 [28] Bouanchaud DH. In-vitro and in-vivo antibacterial activity of

554 quinupristin/dalfopristin. J Antimicrob Chemother. 1997;39 Suppl A:15-21.

555

[29] Lamb HM, Figgitt DP, Faulds D. Quinupristin/dalfopristin: a review of its use in

556

557

[30] Speciale A, La Ferla K, Caccamo F, Nicoletti G. Antimicrobial activity of

558

559 quinupristin/dalfopristin, a new injectable streptogramin with a wide Grampositive spectrum. Int J Antimicrob Agents. 1999;13:21-8.

[31] Pankuch GA, Kelly LM, Lin G, et al. Activities of a new oral streptogramin, XRP 2868, compared to those of other agents against Streptococcus pneumoniae and haemophilus species. Antimicrob Agents Chemother. 2003;47:3270-4.

[32] Eliopoulos GM, Ferraro MJ, Wennersten CB, Moellering RC. In vitro activity of an oral streptogramin antimicrobial, XRP2868, against gram-positive bacteria. Antimicrob Agents Chemother. 2005;49:3034-9.

[33] Goldstein EJC, Citron DM, Merriam CV, et al. Comparative in vitro activities of XRP 2868, pristinamycin, quinupristin-dalfopristin, vancomycin, daptomycin, linezolid, clarithromycin, telithromycin, clindamycin, and ampicillin against anaerobic gram-positive species, actinomycetes, and lactobacilli. Antimicrob Agents Chemother. 2005;49:408-13.

[34] Low DE, Nadler HL. A review of in-vitro antibacterial activity of quinupristin/dalfopristin against methicillin-susceptible and -resistant Staphylococcus aureus. J Antimicrob Chemother. 1997;39 Suppl A:53-8.

[35] Singh KV, Weinstock GM, Murray BE. An Enterococcus faecalis ABC homologue (Lsa) is required for the resistance of this species to clindamycin and quinupristin-dalfopristin. Antimicrob Agents Chemother. 2002;46:1845-50.

[36] Singh KV, Murray BE. Differences in the Enterococcus faecalis lsa locus that influence susceptibility to quinupristin-dalfopristin and clindamycin. Antimicrob Agents Chemother. 2005;49:32-9.

[37] Dina J, Malbruny B, Leclercq R. Nonsense mutations in the lsa-like gene in Enterococcus faecalis isolates susceptible to lincosamides and Streptogramins A. Antimicrob Agents Chemother. 2003;47:2307-9.

[38] Bonfiglio G, Furneri PM. Novel streptogramin antibiotics. Expert Opin Investig Drugs. 2001;10:185-98.

[39] Delgado G, Neuhauser MM, Bearden DT, Danziger LH. Quinupristin-dalfopristin: an overview. Pharmacotherapy. 2000;20:1469-85.

[40] Jensen JS, Cusini M, Gomberg M, Moi H. 2016 European guideline on Mycoplasma genitalium infections. J Eur Acad Dermatol Venereol JEADV. 2016;30:1650-6.*

\footnotetext{
* Pristinamycin could be used to treat Mycoplasma genitalium infections.
} 
605

606

607

608

609

610

611

612

613

614

615

616

617

618

619

620

621

622

623

624

625

626

627

628
[41] Bissessor M, Tabrizi SN, Twin J, et al. Macrolide resistance and azithromycin failure in a Mycoplasma genitalium-infected cohort and response of azithromycin failures to alternative antibiotic regimens. Clin Infect Dis Off Publ Infect Dis Soc Am. 2015;60:1228-36.

[42] Clinical and Laboratory Standards Institute MP. Performance standards for antimicrobial susceptibility testing, M100. 28th ed. S.l.: Clinical and Laboratory Standards Institute; 2018.

[43] Clarebout G, Nativelle E, Bozdogan B, Villers C, Leclercq R. Bactericidal activity of quinupristin-dalfopristin against strains of Staphylococcus aureus with the MLS(B) phenotype of resistance according to the erm gene type. Int J Antimicrob Agents. 2004;24:444-9.

[44] John MA, Pletch C, Hussain Z. In vitro activity of quinupristin/dalfopristin, linezolid, telithromycin and comparator antimicrobial agents against 13 species of coagulase-negative staphylococci. J Antimicrob Chemother. 2002;50:933-8.

[45] Fuchs PC, Barry AL, Brown SD. Bactericidal activity of quinupristin-dalfopristin against Staphylococcus aureus: clindamycin susceptibility as a surrogate indicator. Antimicrob Agents Chemother. 2000;44:2880-2.

[46] Brown J, Freeman BB. Combining Quinupristin/Dalfopristin with Other Agents for Resistant Infections. Ann Pharmacother. 2004;38:677-85.

[47] Eliopoulos GM, Wennersten CB. Antimicrobial activity of quinupristindalfopristin combined with other antibiotics against vancomycin-resistant enterococci. Antimicrob Agents Chemother. 2002;46:1319-24.

[48] Schwarz S, Shen J, Kadlec K,et al. Lincosamides, Streptogramins, phenicols, and pleuromutilins: mode of action and mechanisms of resistance. Cold Spring Harb Perspect Med. 2016;6.

[49] Hershberger E, Donabedian S, Konstantinou K, Zervos MJ. Quinupristindalfopristin resistance in gram-positive bacteria: mechanism of resistance and epidemiology. Clin Infect Dis Off Publ Infect Dis Soc Am. 2004;38:92-8.

[50] Roberts MC. Environmental macrolide-lincosamide-streptogramin and tetracycline resistant bacteria. Front Microbiol. 2011;2:40.

[51] Roberts MC. Update on macrolide-lincosamide-streptogramin, ketolide, and oxazolidinone resistance genes. FEMS Microbiol Lett. 2008;282:147-59.

[52] Hays C, Lienhard R, Auzou M, et al. Erm(X)-mediated resistance to macrolides, lincosamides and streptogramins in Actinobaculum schaalii. J Antimicrob Chemother. 2014;69:2056-60.

[53] Wipf JRK, Schwendener S, Perreten V. The novel macrolide-lincosamidestreptogramin B resistance gene erm(44) is associated with a prophage in Staphylococcus xylosus. Antimicrob Agents Chemother. 2014;58:6133-8. 
629 [54] Wipf JRK, Schwendener S, Nielsen JB, Westh H, Perreten V. The new macrolide-

630

631

632

633

634

635

636

637

638

639

640

641

642

643

644

645

646

647

648

649

650

651

652

653

654

655

656

657

658

659

660

661

662

663

664

665

666

lincosamide-streptogramin B resistance gene erm(45) is located within a genomic island in Staphylococcus fleurettii. Antimicrob Agents Chemother. 2015;59:3578-81.

[55] Wipf JRK, Riley MC, Kania SA, et al. New Macrolide-Lincosamide-Streptogramin B resistance gene erm(48) on the novel plasmid pJW2311 in Staphylococcus xylosus. Antimicrob Agents Chemother. 2017;61.

[56] Cattoir V, Merabet L, Legrand P, Soussy C-J, Leclercq R. Emergence of a Streptococcus pneumoniae isolate resistant to streptogramins by mutation in ribosomal protein L22 during pristinamycin therapy of pneumococcal pneumonia. J Antimicrob Chemother. 2007;59:1010-2.

[57] Sharkey LKR, Edwards TA, O'Neill AJ. ABC-F Proteins mediate antibiotic resistance through ribosomal protection. mBio. 2016;7:e01975.

[58] Kehrenberg C, Schwarz S. Distribution of florfenicol resistance genes fexA and cfr among chloramphenicol-resistant Staphylococcus isolates. Antimicrob Agents Chemother. 2006;50:1156-63.

[59] Wang Y, Zhang W, Wang J, et al. Distribution of the multidrug resistance gene cfr in Staphylococcus species isolates from swine farms in China. Antimicrob Agents Chemother. 2012;56:1485-90.

[60] He T, Wang Y, Schwarz S, Zhao Q, Shen J, Wu C. Genetic environment of the multiresistance gene cfr in methicillin-resistant coagulase-negative staphylococci from chickens, ducks, and pigs in China. Int J Med Microbiol IJMM. 2014;304:257-61.

[61] Toh S-M, Xiong L, Arias CA, et al. Acquisition of a natural resistance gene renders a clinical strain of methicillin-resistant Staphylococcus aureus resistant to the synthetic antibiotic linezolid. Mol Microbiol. 2007;64:1506-14.

[62] Witte W, Cuny C. Emergence and spread of cfr-mediated multiresistance in staphylococci: an interdisciplinary challenge. Future Microbiol. 2011;6:925-31.

[63] Cai JC, Hu YY, Zhou HW, Chen G-X, Zhang R. Dissemination of the same cfrcarrying plasmid among methicillin-resistant Staphylococcus aureus and coagulase-negative staphylococcal isolates in China. Antimicrob Agents Chemother. 2015;59:3669-71.

[64] Kehrenberg C, Schwarz S, Jacobsen L, Hansen LH, Vester B. A new mechanism for chloramphenicol, florfenicol and clindamycin resistance: methylation of $23 \mathrm{~S}$ ribosomal RNA at A2503. Mol Microbiol. 2005;57:1064-73.

[65] Long KS, Poehlsgaard J, Kehrenberg C, Schwarz S, Vester B. The Cfr rRNA methyltransferase confers resistance to Phenicols, Lincosamides, Oxazolidinones, Pleuromutilins, and Streptogramin A antibiotics. Antimicrob Agents Chemother. 2006;50:2500-5.

\footnotetext{
URL: https://mc.manuscriptcentral.com/eri 25 Email: IERZ-peerreview@journals.tandf.co.uk
} 
667 [66] Schwarz S, Werckenthin C, Kehrenberg C. Identification of a plasmid-borne

670

671

672

673

674

675

676

677

678

679

680

681

682

683

684

685

686

687

688

689

690

691

692

693

694

695

696

697

698

699

700

701

702

703

704

705 chloramphenicol-florfenicol resistance gene in Staphylococcus sciuri. Antimicrob Agents Chemother. 2000;44:2530-3.

[67] Murina V, Kasari M, Hauryliuk V, Atkinson GC. Antibiotic resistance ABCF proteins reset the peptidyl transferase centre of the ribosome to counter translational arrest. Nucleic Acids Res. 2018;46:3753-63.

[68] Isnard C, Malbruny B, Leclercq R, Cattoir V. Genetic basis for in vitro and in vivo resistance to lincosamides, streptogramins A, and pleuromutilins (LSAP phenotype) in Enterococcus faecium. Antimicrob Agents Chemother. 2013;57:4463-9.

[69] El Solh N, Allignet J. Staphylococcal resistance to streptogramins and related antibiotics. Drug Resist Updat Rev Comment Antimicrob Anticancer Chemother. 1998;1:169-75.

[70] Leclercq R, Nantas L, Soussy CJ, Duval J. Activity of RP 59500, a new parenteral semisynthetic streptogramin, against staphylococci with various mechanisms of resistance to macrolide-lincosamide-streptogramin antibiotics. J Antimicrob Chemother. 1992;30 Suppl A:67-75.

[71] Dupuis M, Leclercq R. Activity of a new oral streptogramin, XRP2868, against gram-positive cocci harboring various mechanisms of resistance to streptogramins. Antimicrob Agents Chemother. 2006;50:237-42.

[72] Fantin B, Leclercq R, Merlé Y, et al. Critical influence of resistance to streptogramin B-type antibiotics on activity of RP 59500 (quinupristindalfopristin) in experimental endocarditis due to Staphylococcus aureus. Antimicrob Agents Chemother. 1995;39:400-5.

[73] Fantin B, Leclercq R, Garry L, Carbon C. Influence of inducible cross-resistance to macrolides, lincosamides, and streptogramin B-type antibiotics in Enterococcus faecium on activity of quinupristin-dalfopristin in vitro and in rabbits with experimental endocarditis. Antimicrob Agents Chemother. 1997;41:931-5.

[74] Entenza JM, Drugeon H, Glauser MP, Moreillon P. Treatment of experimental endocarditis due to erythromycin-susceptible or -resistant methicillin-resistant Staphylococcus aureus with RP 59500. Antimicrob Agents Chemother. 1995;39:1419-24.

[75] Batard E, Jacqueline C, Boutoille D, et al. Combination of quinupristin-dalfopristin and gentamicin against methicillin-resistant Staphylococcus aureus: experimental rabbit endocarditis study. Antimicrob Agents Chemother. 2002;46:2174-8.

[76] Wang S, Guo Y, Lv J, et al. Characteristic of Enterococcus faecium clinical isolates with quinupristin/dalfopristin resistance in China. BMC Microbiol. 2016;16:246.

[77] Thal LA, Zervos MJ. Occurrence and epidemiology of resistance to virginiamycin and streptogramins. J Antimicrob Chemother. 1999;43:171-6. 
706 [78] Saravolatz LD, Eliopoulos GM. Quinupristin-Dalfopristin and linezolid: evidence 707

[83] Leclercq R, Soussy CJ, Weber P, Moniot-Ville N, Dib C, Groupe d'Etude Multicentrique. [In vitro activity of the pristinamycin against the isolated staphylococci in the french hospitals in 1999-2000]. Pathol Biol (Paris). 2003;51:400-4.

[84] Fritsche TR, Sader HS, Jones RN. Comparative activity and spectrum of broadspectrum beta-lactams (cefepime, ceftazidime, ceftriaxone, piperacillin/tazobactam) tested against 12,295 staphylococci and streptococci: report from the SENTRY antimicrobial surveillance program (North America: 2001-2002). Diagn Microbiol Infect Dis. 2003;47:435-40.

[85] Mendes RE, Sader HS, Deshpande L, Jones RN. Antimicrobial activity of tigecycline against community-acquired methicillin-resistant Staphylococcus aureus isolates recovered from North American medical centers. Diagn Microbiol Infect Dis. 2008;60:433-6.

[86] Flamm RK, Farrell DJ, Mendes RE, Ross JE, Sader HS, Jones RN. LEADER surveillance program results for 2010: an activity and spectrum analysis of linezolid using 6801 clinical isolates from the United States (61 medical centers). Diagn Microbiol Infect Dis. 2012;74:54-61.

[87] Malbruny B, Werno AM, Anderson TP, Murdoch DR, Leclercq R. A new phenotype of resistance to lincosamide and streptogramin A-type antibiotics in Streptococcus agalactiae in New Zealand. J Antimicrob Chemother. 2004;54:1040-4.

[88] Hawkins PA, Law CS, Metcalf BJ, et al. Cross-resistance to lincosamides, streptogramins A and pleuromutilins in Streptococcus agalactiae isolates from the USA. J Antimicrob Chemother. 2017;72:1886-92. 
746 [89] Batah J, Varon E. Rapport d'activité 2017 du Centre National de Référence des Pneumocoques. 2017;84.

748

749

750

751

752

753

754

755

756

757

758

759

760

761

762

763

764

765

766

767

768

769

770

771

772

773

774

775

776

777

778

779

780

781

782

[90] Koechlin C, Kempf JF, Jehl F, Monteil H. Single oral dose pharmacokinetics of the two main components of pristinamycin in humans. J Antimicrob Chemother. 1990;25:651-6.

[91] Bearden DT. Clinical pharmacokinetics of quinupristin/dalfopristin. Clin Pharmacokinet. 2004;43:239-52.

[92] Fantin B, Leclercq R, Ottaviani M, et al. In vivo activities and penetration of the two components of the streptogramin RP 59500 in cardiac vegetations of experimental endocarditis. Antimicrob Agents Chemother. 1994;38:432-7.

[93] Pessey JJ. [Pristinamycin use in the treatment of acute maxillary sinusitis in adults]. Med Mal Infect. 2008;38:9-11.

[94] Gehanno P, Berche P, Hercot 0 , det al. [Efficiency of a four-day course of pristinamycin compared to a five-day course of cefuroxime axetil for acute bacterial maxillary sinusitis in adult outpatients]. Med Mal Infect. 2004;34:293-302.*

\section{* The study evaluate pristinamycin in acute sinusitis, a frequant indication of streptogramin use}

[95] Trémolières F, Mayaud C, Mouton Y, Weber P, Dellatolas F, Caulin E. [Efficacy and safety of pristinamycin vs amoxicillin in community acquired pneumonia in adults]. Pathol Biol (Paris). 2005;53:503-10.

[96] Poirier R, Chardon H, Beraud A, et al. [Efficacy and tolerability of pristinamycin vs amoxicillin-clavulanic acid combination in the treatment of acute communityacquired pneumonia in hospitalized adults]. Rev Pneumol Clin. 1997;53:325-31.

[97] Léophonte P, Chidiac C, Drugeon HB, et al. [Treatment of exacerbations of chronic obstructive pulmonary disease with pristinamycin]. Rev Mal Respir. 2004;21:261-71.

[98] Bernard P, Vaillant L, Martin C, Beylot C, Quentin R, Touron D. [Pristinamycin versus oxacillin in the treatment of superficial pyoderma. A multicenter randomized study in 293 outpatients]. Ann Dermatol Venereol. 1997;124:384-9.

[99] Bernard P, Chosidow O, Vaillant L, French Erysipelas Study Group. Oral pristinamycin versus standard penicillin regimen to treat erysipelas in adults: randomised, non-inferiority, open trial. BMJ. 2002;325:864.

[100] Bernard P, Risse L, Bonnetblanc JM. [Pristinamycin in the treatment of acute bacterial dermohypodermitis in adults. An open study of 42 patients]. Ann Dermatol Venereol. 1996;123:16-20. 
783 [101] Chosidow 0, Bernard P, Berbis P, et al. Cloxacillin versus pristinamycin for

784

785

786

787

788

789

790

791

792

793

794

795

796

797

798

799

800

801

802

803

804

805

806

807

808

809

810

811

812

813

814

815

816

817

818

819

820

821 superficial pyodermas: a randomized, open-label, non-inferiority study. Dermatol Basel Switz. 2005;210:370-4.

[102] Ng J, Gosbell IB. Successful oral pristinamycin therapy for osteoarticular infections due to methicillin-resistant Staphylococcus aureus (MRSA) and other Staphylococcus spp. J Antimicrob Chemother. 2005;55:1008-12.

[103] Valour F, Boibieux A, Karsenty J, et al. Pristinamycin in the treatment of MSSA bone and joint infection. J Antimicrob Chemother. 2016;71:1063-70.

[104] Reid AB, Daffy JR, Stanley P, Buising KL. Use of pristinamycin for infections by gram-positive bacteria: clinical experience at an Australian hospital. Antimicrob Agents Chemother. 2010;54:3949-52.

[105] Ruparelia N, Atkins BL, Hemingway J, Berendt AR, Byren I. Pristinamycin as adjunctive therapy in the management of Gram-positive multi-drug resistant organism (MDRO) osteoarticular infection. J Infect. 2008;57:191-7.

[106] Dancer SJ, Robb A, Crawford A, Morrison D. Oral streptogramins in the management of patients with methicillin-resistant Staphylococcus aureus (MRSA) infections. J Antimicrob Chemother. 2003;51:731-5.

[107] Bradshaw CS, Jensen JS, Waites KB. New horizons in Mycoplasma genitalium treatment. J Infect Dis. 2017;216:S412-S419.

[108] Sethi S, Zaman K, Jain N. Mycoplasma genitalium infections: current treatment options and resistance issues. Infect Drug Resist. 2017;10:283-292.

[109] Drew RH, Perfect JR, Srinath L, Kurkimilis E, Dowzicky M, Talbot GH. Treatment of methicillin-resistant Staphylococcus aureus infections with quinupristindalfopristin in patients intolerant of or failing prior therapy. For the Synercid Emergency-Use Study Group. J Antimicrob Chemother. 2000;46:775-84.

[110] Raad I, Bompart F, Hachem R. Prospective, randomized dose-ranging open phase II pilot study of quinupristin/dalfopristin versus vancomycin in the treatment of catheter-related staphylococcal bacteremia. Eur J Clin Microbiol Infect Dis Off Publ Eur Soc Clin Microbiol. 1999;18:199-202.

[111] Linden PK, Moellering RC, Wood CA, et al. Treatment of vancomycin-resistant Enterococcus faecium infections with quinupristin/dalfopristin. Clin Infect Dis Off Publ Infect Dis Soc Am. 2001;33:1816-23.

[112] Raad I, Hachem R, Hanna H, et al. Prospective, randomized study comparing quinupristin-dalfopristin with linezolid in the treatment of vancomycin-resistant Enterococcus faecium infections. J Antimicrob Chemother. 2004;53:646-9.

[113] Moellering RC, Linden PK, Reinhardt J, Blumberg EA, Bompart F, Talbot GH. The efficacy and safety of quinupristin/dalfopristin for the treatment of infections caused by vancomycin-resistant Enterococcus faecium. Synercid Emergency-Use Study Group. J Antimicrob Chemother. 1999;44:251-61.

URL: https://mc.manuscriptcentral.com/eri 29mail: IERZ-peerreview@journals.tandf.co.uk 
822 [114] Nichols RL, Graham DR, Barriere SL, et al. Treatment of hospitalized patients

823

824

825

826

827

828

829

830

831

832

833

834

835

836

837

838

839

840 with complicated gram-positive skin and skin structure infections: two randomized, multicentre studies of quinupristin/dalfopristin versus cefazolin, oxacillin or vancomycin. Synercid Skin and Skin Structure Infection Group. J Antimicrob Chemother. 1999;44:263-73.

[115] Fagon J, Patrick H, Haas DW, et al. Treatment of gram-positive nosocomial pneumonia. Prospective randomized comparison of quinupristin/dalfopristin versus vancomycin. Nosocomial Pneumonia Group. Am J Respir Crit Care Med. 2000;161:753-62.

[116] Loeffler AM, Drew RH, Perfect JR, et al. Safety and efficacy of quinupristin/dalfopristin for treatment of invasive Gram-positive infections in pediatric patients. Pediatr Infect Dis J. 2002;21:950-6.

[117] Habib G, Lancellotti P, Antunes MJ et al. 2015 ESC Guidelines for the management of infective endocarditis. Eur Heart J. 2015;36:3075-128.

[118] Denis Prevot M, Thillard EM, Walther J, et al. Pristinamycin-induced arthralgia and myalgia: Analysis of the French Pharmacovigilance Database. Med Mal Infect. 2018;48:58-62. 


\section{Legends of the figures}

842 Figure 1. Structure of streptogramins A (right) and B (left).

843

844 Figure 2. Mechanism of action of streptogramins. (A) Normal protein elongation; attachment 845 of tRNAs to the peptidyl transferase center (PTC) and elongation of polypetide chain. Then, 846 the peptide exits through the peptide exit tunnel. (B) Streptogramins could blocked tRNA 847 attachment and prevent early steps of elongation, or interact with the peptide exit tunnel.

848

849

Figure 3. Mechanisms of resistance to streptogramins A and B 


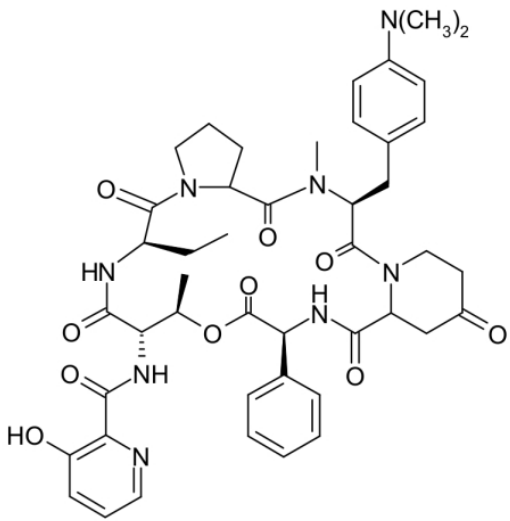

Pristinamycin IA<smiles>CC1CN2CCCC2C(=O)N(C)C1C(=O)N1CC(CCC2CN3CCC2CC3)C(=O)CC1C(=O)NC(C(=O)OC1C(=O)NC(=O)[C@@H](NC(=O)c2ncccc2O)C1C)c1ccccc1</smiles>

Quinupristin<smiles>C/C=C(C)/C=C/CNC(=O)/C=C/[C@H](C)[C@H](OC(=O)C1=CCCN1C(=O)c1coc(CC(=O)C[C@H](O)CC)n1)C(C)C</smiles>

Pristinamycin IIA

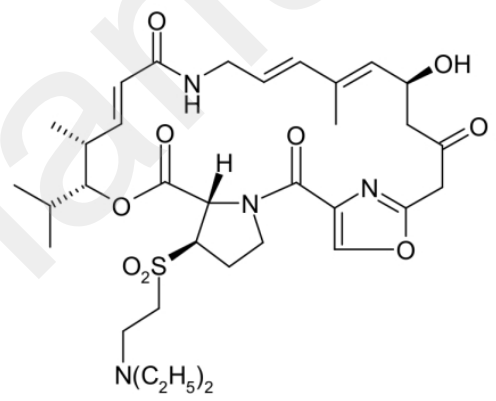

Dalfopristin

Figure 1

$161 \times 150 \mathrm{~mm}(300 \times 300 \mathrm{DPI})$ 
A

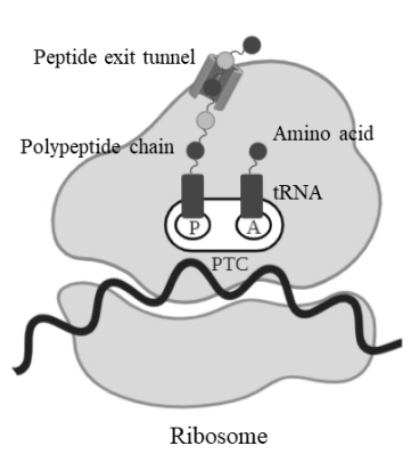

B
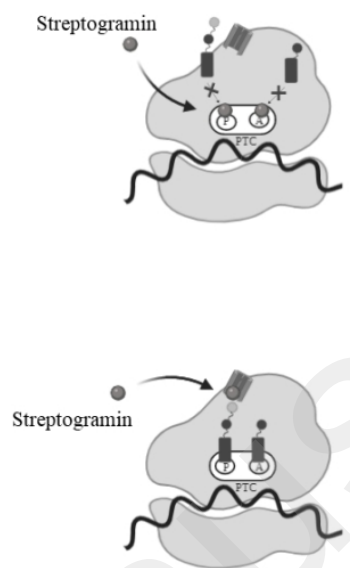

Figure 2

$338 \times 190 \mathrm{~mm}(96 \times 96$ DPI) 


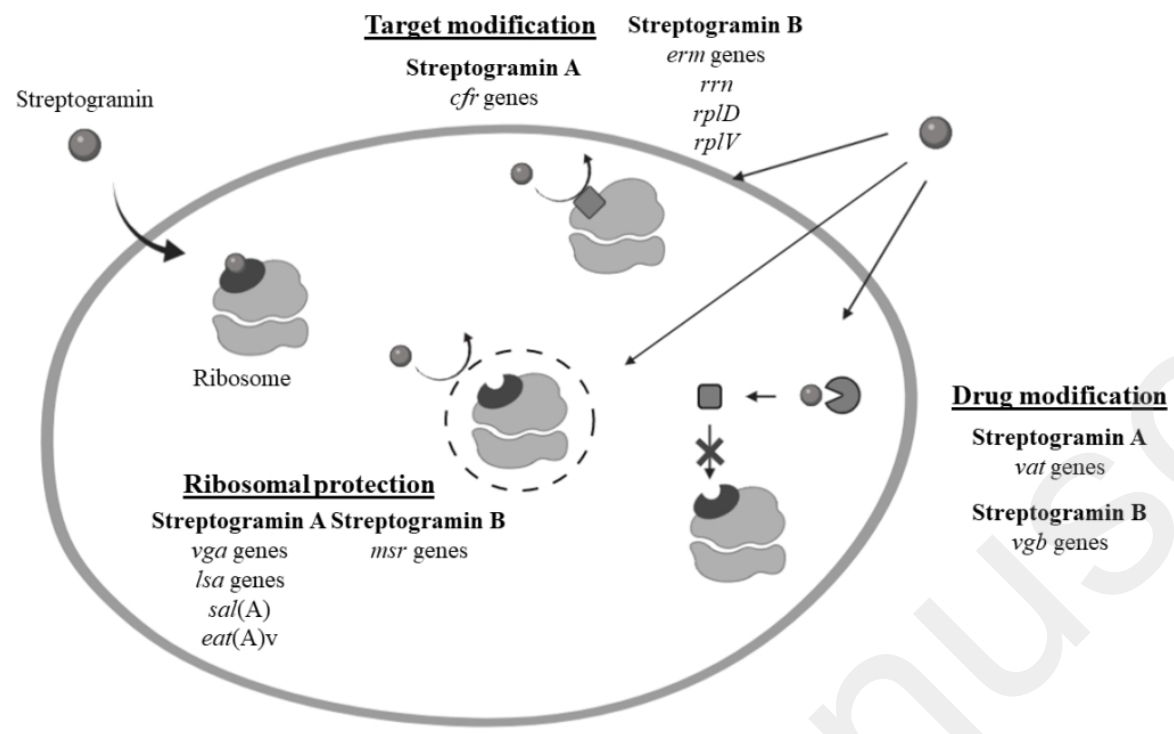

Figure 3

$338 \times 190 \mathrm{~mm}(96 \times 96 \mathrm{DPI})$ 
Table 1: Examples of streptogramins [19,20].

\begin{tabular}{|c|c|c|c|}
\hline \multirow[t]{2}{*}{ Streptogramins } & \multicolumn{2}{|c|}{ Individual components } & \multirow[t]{2}{*}{ Producing organism } \\
\hline & $\mathrm{A}$ & $\mathrm{B}$ & \\
\hline \multicolumn{4}{|l|}{ Natural products } \\
\hline Madumycin & Madumycin II & Madumycin I & Actinomadura flava \\
\hline Mikamycin & Mikamycin A & Mikamycin B & Strepomyces mitakaensis \\
\hline Pristinamycin & $\begin{array}{c}\text { Pristinamycin } \mathrm{II}_{\mathrm{A}}, \mathrm{II}_{\mathrm{B}}, \mathrm{II}_{\mathrm{C}} \text {, } \\
\mathrm{II}_{\mathrm{D}}, \mathrm{II}_{\mathrm{E}}, \mathrm{II}_{\mathrm{F}}, \mathrm{II}_{\mathrm{G}}\end{array}$ & $\begin{array}{c}\text { Pristinamycin } \mathrm{I}_{\mathrm{A}}, \mathrm{I}_{\mathrm{B}}, \mathrm{I}_{\mathrm{C}}, \mathrm{I}_{\mathrm{D}}, \\
\mathrm{I}_{\mathrm{E}}, \mathrm{I}_{\mathrm{F}}, \mathrm{I}_{\mathrm{G}}, \mathrm{I}_{\mathrm{H}}, \mathrm{I}_{\mathrm{I}}\end{array}$ & $\begin{array}{l}\text { Streptomyces } \\
\text { pristinaespiralis }\end{array}$ \\
\hline Synergistin & Synergistin A1, A2 & Synergistin B1, B2, B3 & \\
\hline Vernamycin & Vernamycin A & Vernamycin B $(\alpha, \beta, \gamma, \delta)$ & Streptomyces olivaceus \\
\hline Virginiamycin & Virginiamycin M1, M2 & $\begin{array}{c}\text { Virginiamycin S1, S2, S3, } \\
\text { S4, S5 }\end{array}$ & $\begin{array}{l}\text { Streptomyces loidensis } \\
\text { Streptomyces virginiae }\end{array}$ \\
\hline \multicolumn{4}{|l|}{ Semisynthetic derivatives } \\
\hline $\begin{array}{l}\text { Quinupristin-dalfopristin } \\
\text { (RP 59500) }\end{array}$ & $\begin{array}{l}\text { Dalfopristin } \\
\text { (RP 54476) }\end{array}$ & $\begin{array}{l}\text { Quinupristin } \\
\text { (RP 57669) }\end{array}$ & \\
\hline $\begin{array}{l}\text { Linopristin-flopristin } \\
\text { (XRP 2868) }\end{array}$ & $\begin{array}{c}\text { Flopristin } \\
\text { (RPR 132552) }\end{array}$ & $\begin{array}{c}\text { Linopristin } \\
\text { (RPR 202868) }\end{array}$ & - \\
\hline
\end{tabular}


Table 2: Comparative in vitro activity (MIC in $\mathrm{mg} / \mathrm{l}$ ) of quinupristin-dalfopristin, and pristinamycin against Gram-positive bacteria [31-40].

\begin{tabular}{|c|c|c|c|c|c|c|}
\hline \multirow{2}{*}{$\begin{array}{l}\text { Bacterial species } \\
\text { (no. of tested isolates) }{ }^{a}\end{array}$} & \multicolumn{3}{|c|}{ Quinupristin-Dalfopristin } & \multicolumn{3}{|c|}{ Pristinamycin } \\
\hline & Range & $\mathrm{MIC}_{50}$ & $\mathrm{MIC}_{90}$ & Range & $\mathrm{MIC}_{50}$ & $\mathrm{MIC}_{90}$ \\
\hline MS Staphylococcus aureus (30) & $0.12-0.5$ & 0.25 & 0.5 & $\leq 0.06-1$ & 0.25 & 0.5 \\
\hline MR Staphylococcus aureus (45) & $0.12-1$ & 0.5 & 1 & $0.25-2$ & 1 & 2 \\
\hline Staphylococcus epidermidis (14) & $\leq 0.06-0.12$ & 0.12 & 0.25 & $\leq 0.06-2$ & 0.12 & 1 \\
\hline VS Enterococcus faecalis (24) & $1-32$ & 8 & 16 & $0.5-16$ & 2 & 4 \\
\hline VanA Enterococcus faecalis (10) & 4 & 8 & 8 & $2-4$ & 4 & 4 \\
\hline VanB Enterococcus faecalis (23) & $4-32$ & 16 & 32 & $2-8$ & 8 & 8 \\
\hline VS Enterococcus faecium (30) & $0.5-2$ & 0.5 & 1 & $0.12-2$ & 0.25 & 0.5 \\
\hline VanA Enterococcus faecium (32) & $0.5-32$ & 0.5 & 8 & $0.25-32$ & 0.25 & 4 \\
\hline VanB Enterococcus faecium (31) & $0.25-16$ & 0.5 & 4 & $0.12-4$ & 0.25 & 2 \\
\hline PS Streptococcus pneuтoniae (86) & $\leq 0.06-1$ & 0.5 & 0.5 & $0.12-0.5$ & 0.25 & 0.25 \\
\hline PI Streptococcus pneumoniae (81) & $0.12-1$ & 0.5 & 1 & $0.12-1$ & 0.25 & 0.5 \\
\hline PR Streptococcus pneumoniae (94) & $0.12-1$ & 0.5 & 1 & $0.12-1$ & 0.25 & 0.5 \\
\hline ES Streptococcus pneumoniae (141) & $\leq 0.06-1$ & 0.5 & 0.5 & $0.12-0.5$ & 0.25 & 0.25 \\
\hline ER Streptococcus pneumoniae (120) & $0.25-1$ & 0.5 & 1 & $0.12-1$ & 0.25 & 0.5 \\
\hline Streptococcus pyogenes (27) & $0.25-1$ & 0.25 & 0.5 & $\leq 0.06-0.12$ & 0.12 & 0.12 \\
\hline Streptococcus agalactiae (15) & $0.5-2$ & 1 & 2 & $0.12-0.25$ & 0.25 & 0.25 \\
\hline Viridans streptococci (20) & $0.12-4$ & 1 & 4 & $0.25-1$ & 0.5 & 0.5 \\
\hline Listeria monocytogenes (23) & $0.5-1$ & 1 & 1 & $0.25-0.5$ & 0.5 & 0.5 \\
\hline Corynebacterium jeikeium (10) & $\leq 0.06-1$ & 0.25 & 0.5 & $0.12-0.5$ & 0.12 & 0.5 \\
\hline Actinomyces israelii (13) & $0.12-0.5$ & 0.25 & 0.25 & $\leq 0.03-0.12$ & 0.12 & 0.12 \\
\hline Actinomyces odontolyticus (10) & $0.12-0.5$ & 0.25 & 0.25 & $\leq 0.03-0.12$ & $\leq 0.03$ & 0.12 \\
\hline Clostridium difficile (14) & $0.25-2$ & 0.25 & 1 & $0.12-16$ & 0.12 & 4 \\
\hline Clostridium perfringens (12) & $0.12-0.5$ & 0.25 & 0.25 & 0.12 & 0.12 & 0.12 \\
\hline Finegoldia magna $(11)^{b}$ & $0.25-0.5$ & 0.25 & 0.5 & $0.06-0.12$ & 0.12 & 0.12 \\
\hline Cutibacterium acnes (10) & $\leq 0.03-0.5$ & 0.12 & 0.12 & $\leq 0.03-0.12$ & $\leq 0.03$ & $\leq 0.03$ \\
\hline BLN Haemophilus influenzae (50) & $1-8$ & 2 & 4 & $0.5-2$ & 1 & 2 \\
\hline BLP Haemophilus influenzae (79) & $0.25-8$ & 4 & 4 & $0.12-4$ & 1 & 2 \\
\hline BLNAR Haemophilus influenzae (21) & $1-8$ & 2 & 4 & $0.25-4$ & 1 & 1 \\
\hline BLN Haemophilus parainfluenzae (18) & $1-16$ & 8 & 16 & $0.5-8$ & 4 & 4 \\
\hline BLP Haemophilus parainfluenzae (8) & $2-32$ & 8 & 16 & $1-8$ & 4 & 4 \\
\hline Moraxella catarrhalis (30) & $0.25-2$ & 1 & 1 & $0.06-0.5$ & 0.25 & 0.5 \\
\hline Bordetella pertussis (10) & $0.12-0.25$ & - & - & 0.06 & - & - \\
\hline Neisseria meniingitidis (20) & $0.06-1$ & 0.25 & 0.5 & $0.03-0.25$ & 0.06 & 0.12 \\
\hline Neisseria gonorrhoeae (30) & $0.12-4$ & 0.5 & 1 & $0.06-1$ & 0.12 & 0.5 \\
\hline Bacteroides fragilis group (100) & $0.25-4$ & 2 & 2 & $0.5-8$ & 2 & 4 \\
\hline Bacteroides spp. (50) & $0.03-2$ & 0.125 & 1 & $0.06-4$ & 0.25 & 2 \\
\hline Fusobacterium spp. (40) & $0.06-0.12$ & 0.06 & 0.12 & $0.06-2$ & 0.06 & 0.5 \\
\hline Mycoplasma pneumoniae (20) & $0.03-0.5$ & 0.12 & 0.25 & $0.12-0.5$ & 0.25 & 0.5 \\
\hline Mycoplasma hominis (20) & $0.25-4$ & 1 & 2 & $0.25-2$ & 0.5 & 0.5 \\
\hline Ureaplasma urealyticum (19) & $0.5-2$ & 1 & 2 & $0.25-2$ & 0.5 & 2 \\
\hline Legionella spp. (20) & $0.25-1$ & 0.5 & 0.5 & $0.03-0.12$ & 0.06 & 0.12 \\
\hline Chlamydophila pneumoniae (5) & $2-4$ & - & - & $0.5-1$ & - & - \\
\hline Chlamydia trachomatis (10) & $0.5-1$ & - & - & $0.12-0.25$ & - & - \\
\hline
\end{tabular}

${ }^{a}$ ER: Erythromycin-resistant; ES: Erythromycin-susceptible; MR: Methicillin-resistant; MS: Methicillin-susceptible; PI: Penicillin-intermediate; PR: Penicillin-resistant; PS: Penicillin-susceptible; VS: Vancomycin-susceptible; BLN: $\beta$-lactamase-negative; BLNAR: $\beta$-lactamase-negative ampicillin-resistant; BLP: $\beta$-lactamase-positive. ${ }^{b}$ Formerly Peptostreptococcus magnus. 
Table 3: Mechanisms of resistance to streptogramins in Gram-positive bacteria (http://faculty.washington.edu/marilynr/) [20, 21, 24, 48-68].

\begin{tabular}{|c|c|c|c|}
\hline $\begin{array}{l}\text { Resistance } \\
\text { mechanism }\end{array}$ & Gene(s) & $\begin{array}{l}\text { Resistance } \\
\text { phenotype }^{a}\end{array}$ & Main bacterial species \\
\hline $\begin{array}{l}\text { Streptogramins A } \\
\text { Ribosomal } \\
\text { methylation }\end{array}$ & $c f r, c f r(\mathrm{~B}), c f r(\mathrm{D})$ & $\mathrm{PhLOPS}_{\mathrm{A}}$ & $\begin{array}{l}\text { Staphylococcus spp., Streptococcus spp, } \\
\text { Enterococcus spp. }\end{array}$ \\
\hline Acetylation & $\operatorname{vat}(\mathrm{A})-(\mathrm{E}), \operatorname{vat}(\mathrm{G})$ & $\mathrm{S}_{\mathrm{A}}$ & Staphylococcus spp., Enterococcus spp. \\
\hline $\begin{array}{l}\text { Ribosomal } \\
\text { protection }\end{array}$ & $\begin{array}{l}\operatorname{vga}(\mathrm{A})-(\mathrm{E}), \\
\operatorname{vga}(\mathrm{A})_{\mathrm{V}}, \operatorname{vg} a(\mathrm{~A})_{\mathrm{LC}} \\
\operatorname{lsa}_{(\mathrm{A})-(\mathrm{C})^{c}, l_{\mathrm{L}}(\mathrm{E})} \\
\operatorname{sal}(\mathrm{A}) \\
\operatorname{eat}(\mathrm{A}) \mathrm{v}\end{array}$ & $\begin{array}{l}\mathrm{S}_{\mathrm{A}} \\
\mathrm{LS}_{\mathrm{A}} \\
\mathrm{LS}_{\mathrm{A}} \\
\mathrm{LS}_{\mathrm{A}} \\
\mathrm{LS}_{\mathrm{A}}\end{array}$ & $\begin{array}{l}\text { Staphylococcus spp., Enterococcus spp. } \\
\text { Staphylococcus spp. } \\
\text { Staphylococcus spp., Streptococcus spp, } \\
\text { Enterococcus spp. } \\
\text { Staphylococcus sciuri } \\
\text { Enterococcus faecium }\end{array}$ \\
\hline $\begin{array}{l}\text { Streptogramins B } \\
\text { Ribosomal } \\
\text { methylation }\end{array}$ & erm genes $^{b}$ & $\mathrm{MLS}_{\mathrm{B}}$ & $\begin{array}{l}\text { Staphylococcus spp., Streptococcus spp, } \\
\text { Enterococcus spp., Cutibacterium acnes }\end{array}$ \\
\hline Ribosomal mutation & $\begin{array}{l}r r n(23 \mathrm{~S} \text { rRNA) } \\
r p l D(\mathrm{~L} 4 \text { protein }) \\
r p l V(\mathrm{~L} 22 \text { protein }) \\
\operatorname{vg} b(\mathrm{~A}), \operatorname{vg} b(\mathrm{~B})\end{array}$ & $\begin{array}{l}\mathrm{MLS}_{\mathrm{B}} \\
\mathrm{M} \\
\mathrm{MS}_{\mathrm{B}} \\
\mathrm{S}_{\mathrm{B}}\end{array}$ & $\begin{array}{l}\text { Streptococcus pneumoniae } \\
\text { Streptococcus pneumoniae } \\
\text { Staphylococcus aureus, Streptococcus } \\
\text { pneumoniae } \\
\text { Staphylococcus spp., Enterococcus faecium }\end{array}$ \\
\hline $\begin{array}{l}\text { Ribosomal } \\
\text { protection }\end{array}$ & $m s r(\mathrm{~A})-(\mathrm{D}), m s r(\mathrm{~F})-(\mathrm{H})$ & $\mathrm{MS}_{\mathrm{B}}$ & $\begin{array}{l}\text { Staphylococcus spp., Streptococcus spp., } \\
\text { Enterococcus spp., Macrococcus spp. }\end{array}$ \\
\hline
\end{tabular}

${ }^{a}$ L: Lincosamides; M: Macrolides; O: Oxazolidinones; P: Pleuromutilins; Ph: Phenicols; $\mathrm{S}_{\mathrm{A}}$ : Streptogramins A; $\mathrm{S}_{\mathrm{B}}$ : Streptogramins B.

${ }^{b} \operatorname{erm}(\mathrm{A})-(\mathrm{C}), \operatorname{erm}(\mathrm{F}), \operatorname{erm}(\mathrm{Q}), \operatorname{erm}(\mathrm{T}), \operatorname{erm}(\mathrm{X}), \operatorname{erm}(\mathrm{Y}), \operatorname{erm}(34), \operatorname{erm}(43)-(45), \operatorname{erm}(48), \operatorname{erm}(50)$

${ }^{c} l s a(\mathrm{C})$ is associated with a " $\mathrm{LS}_{\mathrm{A}} \mathrm{P}$ " resistance phenotype 
Table 4: Main pharmacokinetic parameters of streptogramins after a single dose [29, 90-92].

\begin{tabular}{lcccc}
\hline & \multicolumn{2}{c}{$\begin{array}{c}\text { Pristinamycin } \\
(2 \mathrm{~g}, \mathrm{PO})\end{array}$} & \multicolumn{2}{c}{$\begin{array}{c}\text { Quinupristin-Dalfopristin (30:70) } \\
(7.5 \mathrm{mg} / \mathrm{kg}, \mathrm{IV})\end{array}$} \\
\cline { 2 - 5 } Parameter $^{a}$ & $\mathrm{PI}_{\mathrm{A}}$ & $\mathrm{PII}_{\mathrm{A}}$ & Quinupristin & Dalfopristin \\
& & & & \\
\hline $\mathrm{C}_{\max }(\mathrm{mg} / \mathrm{L})$ & 0.8 & 0.6 & $2.3-2.7$ & $6.1-8.2$ \\
$\mathrm{t}_{\max }(\mathrm{h})$ & 3.2 & 3.1 & 0.9 & 1.1 \\
$\mathrm{AUC}(\mathrm{mg} \bullet \mathrm{h} / \mathrm{L})$ & 2.2 & 1.2 & $2.7-3.3$ & $6.5-7.7$ \\
$\mathrm{t}_{1 / 2}(\mathrm{~h})$ & 4 & 2.8 & $0.9-1.3$ & $0.7-1.1$ \\
$\mathrm{CL}(\mathrm{L} / \mathrm{h} / \mathrm{kg})$ & - & - & $0.7-0.9$ & $0.7-0.8$ \\
$\mathrm{~V}_{\mathrm{d}}(\mathrm{L} / \mathrm{kg})$ & - & - & 0.45 & 0.24 \\
$\mathrm{~PB}(\%)$ & $40-45$ & $70-80$ & $55-78$ & $11-26$ \\
$\mathrm{FE}(\%)$ & - & - & 75 & 77 \\
$\mathrm{UE}(\%)$ & - & - & 15 & 19 \\
\hline
\end{tabular}

${ }^{a}$ AUC: area under the concentration-time curve; CL: Systemic clearance; $\mathrm{C}_{\max }$ : Maximal plasma concentration; FE: Excretion in the faeces; IV: Intravenous; PB: Protein binding; PO: per os; $\mathrm{t}_{1 / 2}$ : Plasmatic half-life; UE: Excretion in the urine; $\mathrm{V} d$ : Volume of distribution. 
Table 5: Main clinical trials assessing the efficacy of pristinamycin [93-101] and quinupristin-dalfopristin [109-115].

\begin{tabular}{|c|c|c|c|c|c|}
\hline \multirow[t]{2}{*}{ Reference } & \multirow[t]{2}{*}{ No. of patients } & \multirow[t]{2}{*}{ Drug and dosage ${ }^{b}$} & \multirow{2}{*}{$\begin{array}{l}\text { Duration } \\
\text { (days) }\end{array}$} & \multicolumn{2}{|c|}{ Results $(\%)^{c}$} \\
\hline & & & & $\begin{array}{l}\text { Clinical } \\
\text { success }\end{array}$ & $\begin{array}{l}\text { Bacteriologic } \\
\text { al success }\end{array}$ \\
\hline \multicolumn{6}{|l|}{ Acute sinusitis } \\
\hline \multirow{2}{*}{ Pessey et al. [93] } & 160 & PRI 2g/d & $7-9$ & $73-84$ & - \\
\hline & 148 & CXM $500 \mathrm{mg} / \mathrm{d}$ & $8-10$ & $75-87$ & - \\
\hline \multirow[t]{2}{*}{ Gehanno et al. [94] } & 250 & PRI $2 \mathrm{~g} / \mathrm{d}$ & 4 & $87-91$ & 87 \\
\hline & 235 & CXM $500 \mathrm{mg} / \mathrm{d}$ & 5 & $86-91$ & 88 \\
\hline \multicolumn{6}{|c|}{ Community-acquired pneumonia } \\
\hline \multirow[t]{2}{*}{ Poirier et al. [96] } & 92 & PRI $2 \mathrm{~g} / \mathrm{d}$ & $10-14$ & $84-85$ & - \\
\hline & 88 & $\mathrm{AMC} 2 \mathrm{~g} / \mathrm{d}$ & $10-14$ & 84 & - \\
\hline \multirow[t]{2}{*}{ Trémolières et al. [95] } & 170 & PRI 3 g/d & $7-10$ & $80-88$ & 82 \\
\hline & 169 & $\operatorname{AMX} 3 \mathrm{~g} / \mathrm{d}$ & $7-10$ & $83-88$ & 88 \\
\hline \multicolumn{6}{|c|}{ Acute exacerbations of $\mathrm{COPD}^{a}$} \\
\hline \multirow[t]{2}{*}{ Léophonte et al. [97] } & 239 & PRI $3 \mathrm{~g} / \mathrm{d}$ & 4 & 87 & 85 \\
\hline & 236 & AMC $2 \mathrm{~g} / \mathrm{d}$ & 8 & 88 & 78 \\
\hline \multicolumn{6}{|c|}{ Skin and soft-tissue infections } \\
\hline Bernard et al. [98] & 42 & PRI 3 g/d & up to 10 & 86 & - \\
\hline \multirow[t]{2}{*}{ Bernard et al. [99] } & 151 & PRI $2 \mathrm{~g} / \mathrm{d}$ & 10 & 87 & - \\
\hline & 142 & OXA $2 \mathrm{~g} / \mathrm{d}$ & 10 & 90 & - \\
\hline \multirow[t]{2}{*}{ Bernard et al. [100] } & 138 & PRI $2-3 \mathrm{~g} / \mathrm{d}$ & 14 & $65-81$ & - \\
\hline & 150 & $\begin{array}{c}\text { PG 10-20 MIU/d - PV 3-6 } \\
\text { MIU/d }\end{array}$ & 14 & $53-67$ & - \\
\hline \multirow[t]{2}{*}{ Chosidow et al. [101] } & 163 & & 14 & 81 & - \\
\hline & 171 & $\begin{array}{l}\text { PRI } 2 \mathrm{~g} / \mathrm{d} \\
\text { CLO } 2 \mathrm{~g} / \mathrm{d}\end{array}$ & 14 & 83 & - \\
\hline \multicolumn{6}{|l|}{ MRSA infections } \\
\hline Drew et al. [109] & 90 & QD $7.5 \mathrm{mg} / \mathrm{kg} \mathrm{q} 8 \mathrm{~h}$ & 28 & $74-76$ & $67-71$ \\
\hline \multicolumn{6}{|c|}{ Catheter-related staphylococcal bacteremia } \\
\hline \multirow[t]{3}{*}{ Raad et al. [110] } & 11 & QD 5 mg/kg q8h & 7 & $27-50$ & - \\
\hline & 15 & QD $7.5 \mathrm{mg} / \mathrm{kg} \mathrm{q} 8 \mathrm{~h}$ & 7 & $27-57$ & - \\
\hline & 13 & VA 1 g q12h & 1 & $15-50$ & - \\
\hline \multicolumn{6}{|l|}{ VRE infections } \\
\hline Linden et al. [111] & 396 & QD $7.5 \mathrm{mg} / \mathrm{kg} \mathrm{q} 8 \mathrm{~h}$ & 20 & $51-69$ & $60-68$ \\
\hline Moellering et al. [113] & 396 & QD $7.5 \mathrm{mg} / \mathrm{kg}$ q $8 \mathrm{~h}$ or $\mathrm{q} 12 \mathrm{~h}$ & 14 & $55-74$ & 61 \\
\hline \multirow[t]{2}{*}{ Raad et al. [112] } & 21 & QD $7.5 \mathrm{mg} / \mathrm{kg} \mathrm{q} 8 \mathrm{~h}$ & 11 & 43 & 71 \\
\hline & 19 & LIN $600 \mathrm{mg} \mathrm{q} 12 \mathrm{~h}$ & 15 & 58 & 89 \\
\hline \multicolumn{6}{|l|}{ Complicated SSSTIs } \\
\hline \multirow[t]{2}{*}{ Nichols et al. [114] } & 450 & QD $7.5 \mathrm{mg} / \mathrm{kg} \mathrm{q} 12 \mathrm{~h}$ & 7 & 68 & $46-66$ \\
\hline & 443 & $\begin{array}{c}\text { OXA } 2 \text { g q6h, VAN } 1 \text { g q12h, } \\
\text { or CFZ } 1 \text { g q } 8 \mathrm{~h}\end{array}$ & 8 & 71 & $48-73$ \\
\hline \multicolumn{6}{|c|}{ Nosocomial pneumonia } \\
\hline Fagon et al. [115] & 150 & QD $7.5 \mathrm{mg} / \mathrm{kg} \mathrm{q} 8 \mathrm{~h}+\mathrm{ATM} 2 \mathrm{~g}$ & 10 & $43-56$ & $53-59$ \\
\hline & 148 & $\begin{array}{c}\mathrm{q} 8 \mathrm{~h} \\
\text { VAN } 1 \mathrm{~g} \mathrm{q} 12 \mathrm{~h}+\text { ATM } 2 \mathrm{~g} \mathrm{q} 8 \mathrm{~h}\end{array}$ & 9 & $45-58$ & $55-64$ \\
\hline Community acquired & eumonia & & & & \\
\hline $\begin{array}{l}\text { Not published } \\
\text { (NCT00653172) }\end{array}$ & 302 & $\begin{array}{l}\text { NXL103 } 500 \text { mg q12h } \\
\text { NXL103 } 600 \text { mg q12h } \\
\text { Comparator q12h }\end{array}$ & NA & NA & NA \\
\hline
\end{tabular}


${ }^{a}$ COPD: Chronic obstructive pulmonary disease.

${ }^{b}$ AMC: Amoxicillin-clavulanate; AMX: Amoxicillin; ATM: Aztreonam; CFZ: cefazolin; CLO: Cloxacillin; CXM: Cefuroxime axetil; LIN: Linezolid; OXA: Oxacillin; PG: Penicillin G; PV: Penicillin V; PRI: Pristinamycin; QD: Quinupristin-dalfopristin; VAN: Vancomycin

${ }^{c}$ Success rates observed in per-protocol and/or intention-to-treat populations (end of treatment and/or follow-up).

NA: not available. 